\title{
Colloidal lead halide perovskite nanocrystals: synthesis, optical properties and applications
}

\author{
He Huang ${ }^{1}$, Lakshminarayana Polavarapu ${ }^{2}$, Jasmina A Sichert ${ }^{2}$, Andrei S Susha ${ }^{1}$, Alexander S Urban ${ }^{2}$ and \\ Andrey L Rogach ${ }^{1}$
}

Lead halide perovskite nanocrystals (NCs) are receiving a lot of attention nowadays, due to their exceptionally high photoluminescence quantum yields reaching almost $100 \%$ and tunability of their optical band gap over the entire visible spectral range by modifying composition or dimensionality/size. We review recent developments in the direct synthesis and ion exchange-based reactions, leading to hybrid organic-inorganic $\left(\mathrm{CH}_{3} \mathrm{NH}_{3} \mathrm{PbX}_{3}\right)$ and all-inorganic $(\mathrm{CsPbX})$ lead halide $(\mathrm{X}=\mathrm{Cl}$, $\mathrm{Br}, \mathrm{I})$ perovskite NCs, and consider their optical properties related to quantum confinement effects, single emission spectroscopy and lasing. We summarize recent developments on perovskite NCs employed as an active material in several applications such as light-emitting devices, solar cells and photodetectors, and provide a critical outlook into the existing and future challenges. NPG Asia Materials (2016) 8, e328; doi:10.1038/am.2016.167; published online 18 November 2016

\section{INTRODUCTION}

Metal halide perovskite materials have attracted great scientific and technological interest in recent years, due to their attractive optical and electronic properties ${ }^{1-4}$ combined with low cost and solution processability, which greatly contribute to their high potential for photovoltaic and light-emitting devices (LEDs). ${ }^{1,5-13}$ The earliest scientific work on perovskites was conducted in the late 70 s by Weber, ${ }^{14-16}$ who characterized these materials in detail. Significant advances were made in the 90 s and 2000 s by Mitzi et al. ${ }^{17-19}$ leading to the first implementation of perovskites in devices. Interest seemed to subside for a while until the first reports on the utilization of organic-inorganic lead halide perovskites as sensitizers in solar cells in 2009 (Kojima et al. ${ }^{6}$ ) and the demonstration of their light emission in 2012. ${ }^{20}$ Since then, many studies have contributed toward the fundamental understanding of this fascinating material and to its various technological applications as well. Halide perovskites have a general formula of $\mathrm{ABX}_{3}$, where $\mathrm{A}$ and $\mathrm{B}$ are monovalent and divalent cations, respectively, and $\mathrm{X}$ is a monovalent halide $(\mathrm{Cl}, \mathrm{Br}, \mathrm{I})$ anion. The three-dimensional (3D) crystal structure of lead halide perovskites is shown in Figure 1a, where the B cation, commonly $\mathrm{Pb}$, but also $\mathrm{Sn}$, is coordinated to six halide ions in an octahedral configuration. The octahedra are corner-sharing, with the A cation located in between those octahedra. ${ }^{21}$ Lead halide perovskites are further classified into either organic-inorganic (hybrid) or all-inorganic, depending on whether the A cation is an organic molecule, most commonly methylammonium $\left(\mathrm{MA}, \mathrm{CH}_{3} \mathrm{NH}_{3}{ }^{+}\right)$, or an inorganic cation (commonly $\mathrm{Cs}^{+}$), respectively. The optical and electronic properties of perovskites are tunable by varying the composition of constituted halide ions and to a smaller degree of the cations. ${ }^{22,23}$ In addition, the size and dimensionality of perovskites can also be used to tune their optical properties, similar to conventional metal chalcogenide semiconductors. ${ }^{24,25}$ Although perovskites can be obtained with dimensionality ranging from the $3 \mathrm{D}$ to $0 \mathrm{D}$ by varying the synthetic conditions used (Figure 1b), they have a strong tendency to form layered two-dimensional (2D) and quasi-2D structures (Figure 1c). ${ }^{25-27}$ Recent studies have shown that colloidal perovskite nanocrystals (NCs) can exhibit very high photoluminescence quantum yields (PL QY). ${ }^{23-25,28-30}$ Moreover, they show strong quantum confinement effects when their dimensionality changes from $3 \mathrm{D}$ to 2D, offering additional tunability of optical properties. Perovskite NCs have already shown great promise in many applications such as lasers, LEDs and photovoltaic devices. ${ }^{10,23,31-38}$ Even though the research on perovskite NCs is still in its starting stage, they are expected to have a significant role in the development of modern nanoscience and nanotechnology in the near future. This review provides an overview of the up-to-date developments in the synthesis of hybrid organicinorganic and all-inorganic perovskite NCs, their attractive optical properties and related emerging applications. After considering different synthetic approaches for the preparation of perovskite NCs with tunable optical properties (both direct synthesis and ion exchange based routes), we follow-up with a discussion of quantum confinement effects, single-particle emission and lasing studies. We

\footnotetext{
${ }^{1}$ Department of Physics and Materials Science, and Centre for Functional Photonics (CFP), City University of Hong Kong, Kowloon Tong, Hong Kong and ${ }^{2}$ Department of Physics and CeNS, Ludwig-Maximilians-Universität München, Munich, Germany

Correspondence: Dr AS Urban, Department of Physics and CeNS, Ludwig-Maximilians-Universität München, Amalienstrasse 54, Munich 80799, Germany.

E-mail: urban@Imu.de

or Professor AL Rogach, Department of Physics and Materials Science, and Centre for Functional Photonics (CFP), City University of Hong Kong, 83 Tat Chee Avenue, Kowloon Tong, Hong Kong.

E-mail: andrey.rogach@cityu.edu.hk

Received 22 April 2016; revised 22 July 2016; accepted 9 August 2016
} 
a
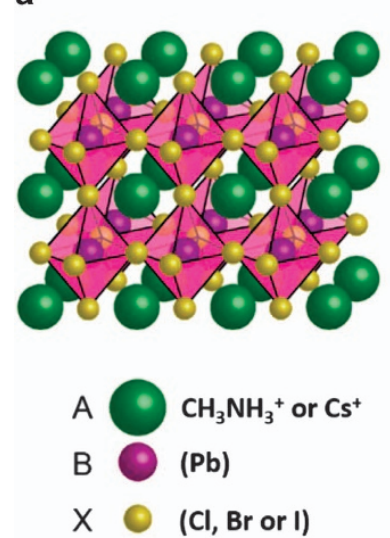

b
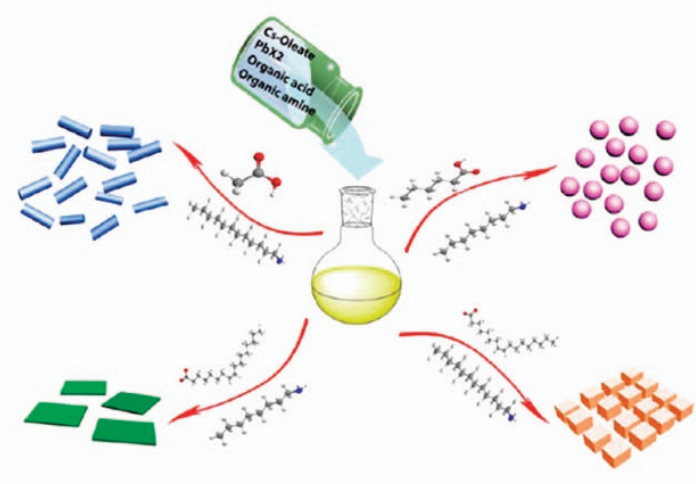

C

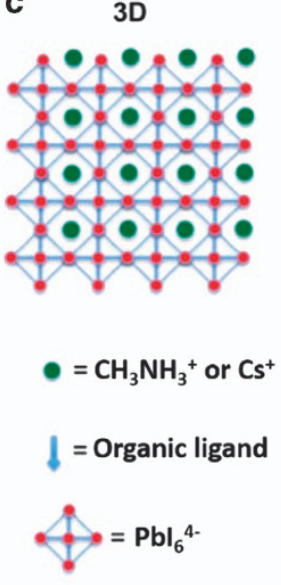

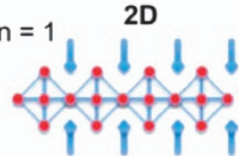
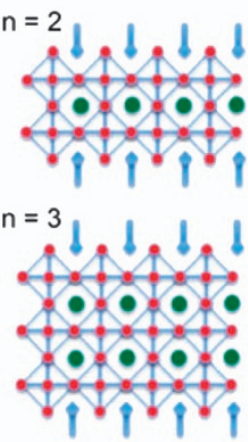

Figure 1 (a) Illustration of the perovskite crystal structure. Adapted from Christians et al. ${ }^{21}$ (b) Tuning of the dimensionality of inorganic perovskites by varying the organic ligands used. Reproduced from Sun et al. ${ }^{26}$ (c) Schematic representation of 3D and (quasi)-2D layered perovskite nanostructures. Reproduced from Wu et al. ${ }^{27}$

summarize recent developments on perovskite NCs employed as active materials in several applications such as LEDs, solar cells and photodetectors, and provide a critical outlook into the existing and future challenges.

\section{SYNTHESIS OF PEROVSKITE NCs}

\section{Direct synthesis of hybrid organic-inorganic perovskite NCs}

MA lead halide perovskite $\left(\mathrm{MAPbX}_{3}\right)$ nanoparticles were first explored as components of mesoporous titania-based dye-sensitized solar cells in 2009. ${ }^{6}$ By spin-coating a precursor solution containing MA halide and $\mathrm{PbX}_{2}$ onto a $\mathrm{TiO}_{2}$ thin film, perovskite NCs of $2-3 \mathrm{~nm}$ in size were formed. In 2012, a strong PL from such nanoparticles was observed, again in a mesoporous material, in this case synthesized by a template method. ${ }^{20}$ The two methods were similar, with a precursor solution spin-coated onto a porous $\mathrm{Al}_{2} \mathrm{O}_{3}$ film and a rapid crystallization of the perovskite on evaporation of the solvent in the latter case. This also constituted the first report on the preparation of luminescent perovskite NCs.

The first solution-based synthesis of colloidal $\mathrm{MAPbBr}_{3} \mathrm{NCs}$ was carried out by the Pérez-Prieto and colleagues, ${ }^{30}$ who employed medium-length alkyl chain organic ammonium cations, octylammonium bromide and octadecylammonium bromide as capping ligands to obtain luminescent NCs via the solvent-induced reprecipitation method. The role of these ligands was to provide a self-termination of the crystallization, leading to the formation of discrete nanoparticles in solution. We note that such ligands had been used previously to fabricate $2 \mathrm{D}$ or quasi-2D layered perovskite materials in the early 90s. ${ }^{39-43}$ The NC dispersions were stable for at least 3 months. The absorption and PL peaks of these highly crystalline (Figure 2a) $\mathrm{MAPbBr}_{3} \mathrm{NCs}$ were at 527 and $530 \mathrm{~nm}$, respectively (Figure 2b), with a PLQY of $\sim 20 \%$. The same group further enhanced the PLQY of these NCs to $83 \%$ by optimizing the molar ratio of octylammonium bromide:MA bromide: $\mathrm{PbBr}_{2} \quad(8: 12: 5)$ in a typical reprecipitation method, while maintaining the 1 -octadecene: $\mathrm{PbBr}_{2}$ molar ratio of 62.6:1.0. ${ }^{28}$ They focused on improving the organic capping of the bromide perovskite NCs, taking into account the fact that surface states would be highly accessible for passivation treatment. This resulted in easily dispersible, strongly luminescent $\mathrm{MAPbBr}_{3} \mathrm{NCs}$ (Figure 2c). Some rectangular features were visible in electron microscopy images along with spherical nanoparticles, but especially also behind them (Figure 2d), hinting at a more complex morphology of the obtained NCs, which we will discuss in detail further below.

This synthetic approach was subsequently adopted by several groups, leading, for example, to the demonstration of efficient perovskite-based chemical sensors. ${ }^{44}$ Luo et al. ${ }^{45}$ used either octylammonium bromide or octadecylammonium bromide to produce perovskite NCs of 3.9 or $6.5 \mathrm{~nm}$ size, respectively, by means of the reprecipitation method. Although no mechanism for the size control was provided, we anticipate that the difference in size of NCs with different ligands was caused by their difference in ligand binding kinetics. The high solubility of longer hydrophobic chain ligands facilitates the increase of NC size compared with the size of NCs obtained by using short hydrophobic chain ligands. However, an indepth study of the mechanism behind the size/shape-controlled growth of perovskite NCs would be highly valuable. Tyagi et al. ${ }^{46}$ employed a similar approach, synthesizing colloidal nanoplatelets of $\mathrm{MAPbBr}_{3}$. They claimed that the excitonic-like features previously attributed to quantum confinement in spherical $\mathrm{MAPbBr}_{3}$ nanoparticles were in fact a property of the nanoplatelets with decremental thickness, down to a single unit cell. They found that the absorption peak of their perovskite $\mathrm{NC}$ dispersion was blue-shifted by $0.5 \mathrm{eV}$ with respect to the absorption onset of the bulk $\mathrm{MAPbBr}_{3}$. The fact that absorption and PL emission maxima were separated by $100 \mathrm{~nm}$ indicated that the dispersions were not phase pure, but rather consisted of nanoplatelets of varying thickness, where near-field energy transfer and reabsorption led to this large energetic separation. By systematically varying the ratio of the organic cations used (octylammonium and MA). Sichert et al. ${ }^{25}$ showed how the perovskite NCs gradually decrease in thickness from large cubic crystals to ultrathin nanoplatelets down to a thickness of only a single perovskite unit cell. The octylammonium molecule is too large to fit into the perovskite crystal structure and so leads to termination of the crystal growth on binding to the perovskite, however predominantly in one direction. The researchers were able to assign individual PL peaks to perovskite nanoplatelets of incremental thickness, confirming this with quantum-confinement calculations, as will be presented in more detail later on.

Zhang et al. developed a ligand-assisted re-precipitation technique to produce brightly luminescent colloidal $\mathrm{MAPbBr}_{3} \mathrm{NC}$ with a PLQY up to $70 \% .{ }^{23}$ Unlike the study by Pérez-Prieto and colleagues, ${ }^{30}$ 
a

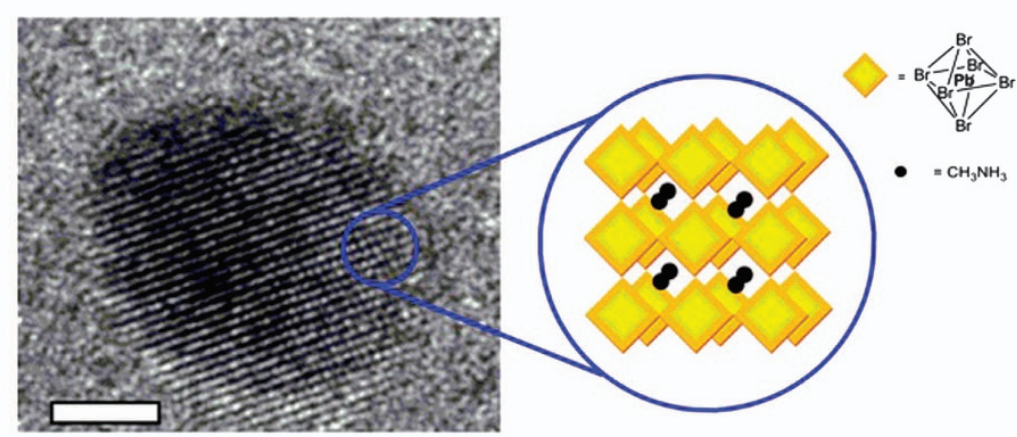

b
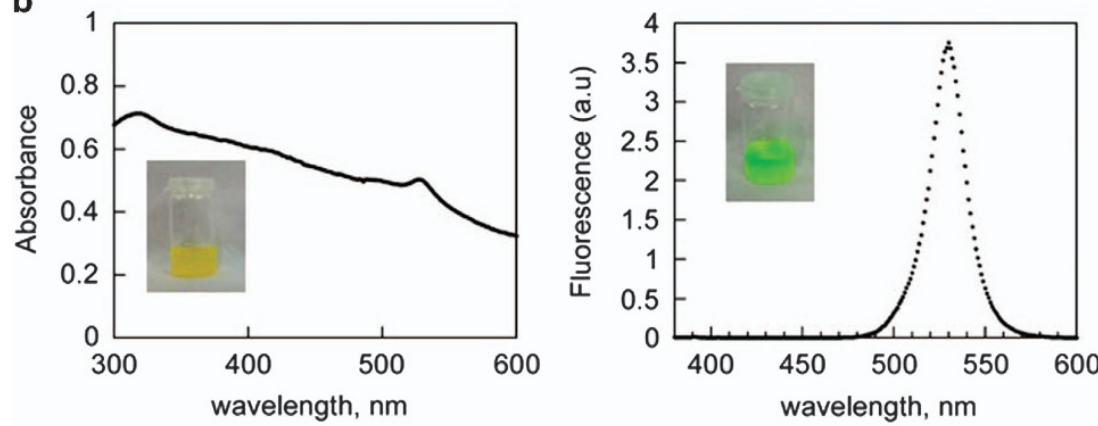

C

d
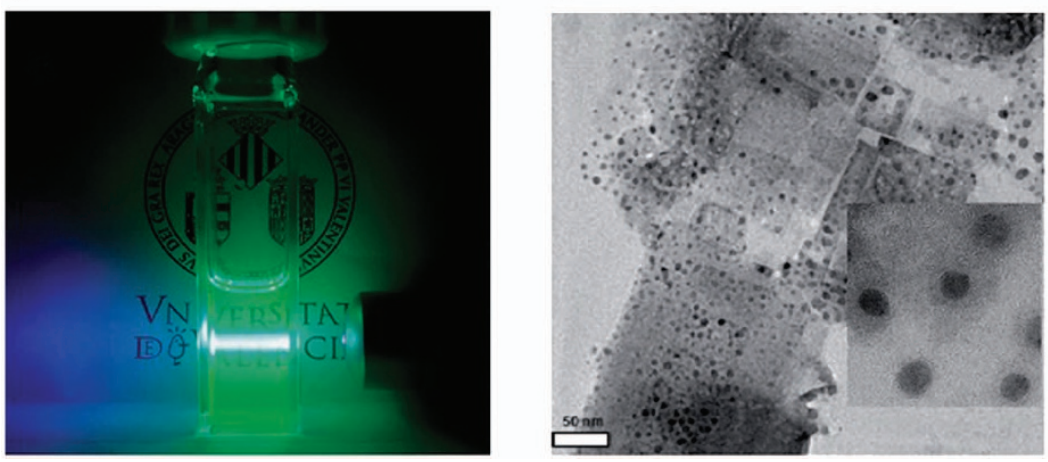

Figure 2 (a) High-resolution TEM image of a single, highly crystalline $\mathrm{MAPbBr}_{3} \mathrm{NC}$ (scale bar: $2 \mathrm{~nm}$ ), shown along with a schematic representation of the perovskite unit cell. (b) UV-visible absorption (left) and $\mathrm{PL}$ spectra (right) of $\mathrm{MAPbBr}_{3} \mathrm{NCs}$ in toluene. Insets show photographs of the respective solution under ambient light and $365 \mathrm{~nm}$ UV lamp. Reproduced from Schmidt et al. ${ }^{30}$ (c) Image of the toluene dispersion of $\mathrm{MAPbBr}_{3} \mathrm{NCs}$ under UV-laser pointer excitation. (d) TEM images of perovskite NCs. Adapted from Gonzalez-Carrero et al. ${ }^{28}$

they choose a reverse way of the reagent mixing: the nanoparticles were formed with n-octylamine and oleic acid as ligands through addition of the perovskite precursors in a good solvent, for example, dimethylformamide or $\gamma$-butyrolactone, into a bad solvent, for example, toluene or acetone, as shown in Figure 3a. It was assumed that n-octylamine controls the kinetics of crystallization and mainly contributes to the size control of NCs formed, whereas oleic acid suppresses aggregation effects and ensures their colloidal stability. From transmission electron microscope (TEM) studies, $\mathrm{MAPbBr}_{3}$ NCs were quasi-spherical and had an average diameter of $3.3 \pm 0.7 \mathrm{~nm}$ (Figure $3 \mathrm{~b}$ ). The authors reasoned that the increased PLQY of the NCs with respect to micrometer-sized bulk perovskite particles resulted from higher excitonic binding energies of up to nearly $400 \mathrm{meV}$, when the size of the NCs approached the Bohr radius of the respective perovskite, on the order of 13-30 $\AA$, depending on the material. ${ }^{25,47,48}$ By replacing the bromide anion with chloride or iodide, or by using mixtures of the three anions, the authors were able to obtain perovskite $\mathrm{NC}$ dispersions emitting throughout the full range of the visible spectrum (Figure 3c). The average PL lifetimes of these NCs were considerably shorter than for the respective bulk films.

Signs of strong 3D quantum confinement in $0 \mathrm{D}$ perovskite NCs were recently observed in the work by Huang et al. ${ }^{29}$ (Figure 3d). Herein, the re-precipitation technique was used to prepare $\mathrm{MAPbBr}_{3}$ NCs with tunable emission by altering the temperature of the bad solvent. A certain amount of the perovskite precursor solution with oleylamine as the organic ligand was quickly injected under vigorous stirring into the toluene, which had been pre-cooled or heated to specific temperatures between 0 and $60^{\circ} \mathrm{C}$. The PL emission wavelength of the resulting NCs ranged from $475-520 \mathrm{~nm}$, with a high PLQY of 74 to $93 \%$, and short radiative lifetimes of only $13-27 \mathrm{~ns}$ in comparison with non-radiative lifetimes of $100 \mathrm{~ns}$ and longer.

Methods such as emulsion synthesis ${ }^{49}$ and electrospray technique coupled antisolvent-solvent extraction ${ }^{50}$ have been used for the synthesis of perovskite NCs of different morphologies, mostly yielding rather polydisperse nanoparticles. It has been shown that nearly 
a
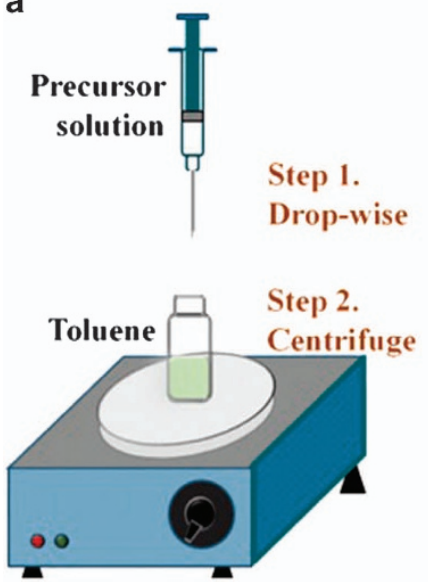

b
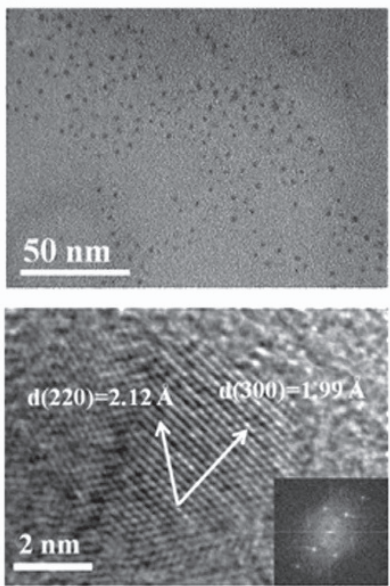

C
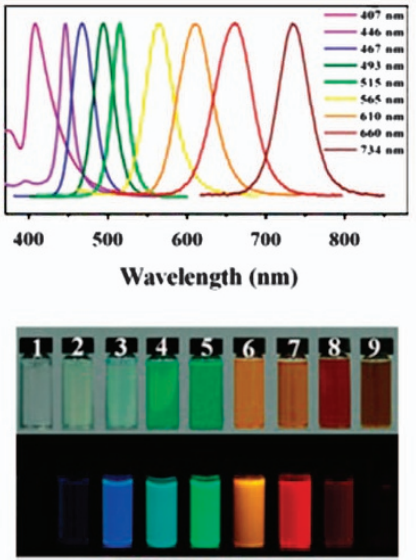

d
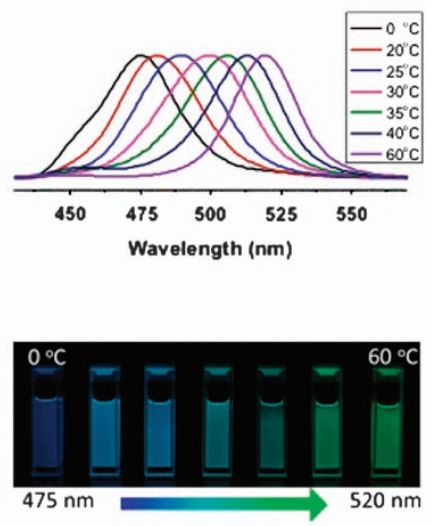

Figure 3 (a) Schematics of ligand-assisted re-precipitation (LARP) technique used to produce MAPbX ${ }_{3}$ NCs. (b) TEM and high-resolution TEM image of the resulting $\mathrm{MAPbBr}_{3} \mathrm{NCs}$. The inset is the corresponding FFT image. (c) PL spectra and optical images of color-tunable MAPbX $\mathrm{X}_{3} \mathrm{NCs}$ produced by LARP technique, under room light and UV lamp. Reproduced from Zhang et al. ${ }^{23}$ (d) PL spectra and photograph of size-tunable emission of strongly emitting $\mathrm{MAPbX}_{3} \mathrm{NCs}$, where the size was controlled by reaction temperature. Reproduced from Huang et al. ${ }^{29}$

a

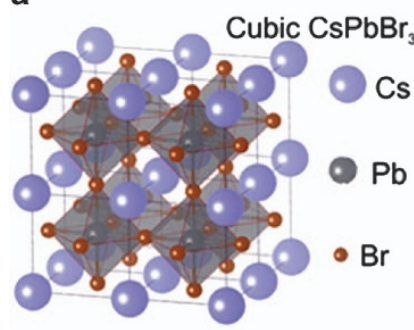

b
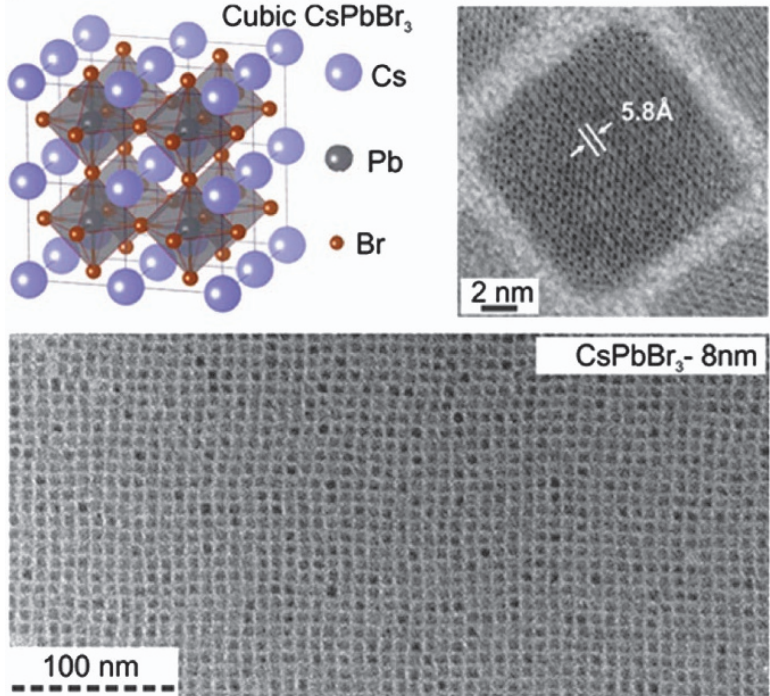

C

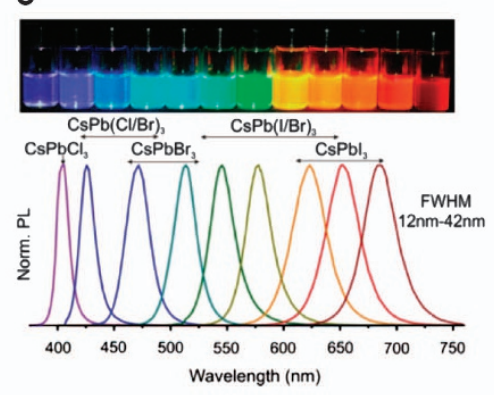

d

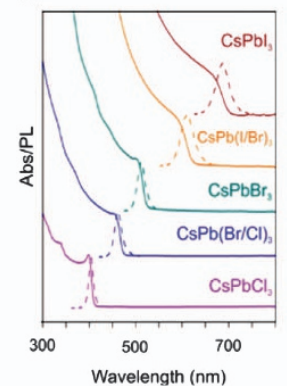

e

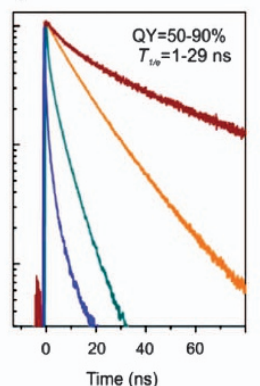

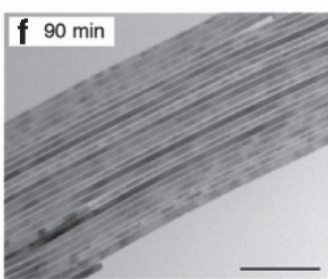
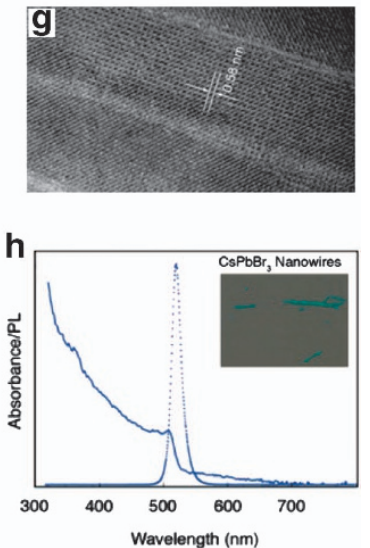

Figure 4 (a) Schematics of the cubic $\mathrm{CsPbBr}_{3}$ perovskite lattice. (b) High-resolution TEM and TEM images of $\mathrm{CsPbBr}_{3} \mathrm{NCs}$. (c) $\mathrm{Photograph}$ of $\mathrm{CsPbX} \mathrm{NC}_{3}$ solutions taken under UV lamp, with size- and composition-tunable bandgap and corresponding PL spectra. (d) Absorption and PL spectra of CsPbX $\mathrm{NCs}_{3}$ with different $\mathrm{X}$ anions employed. (e) Time-resolved PL decays of $\mathrm{CsPbBr}_{3} \mathrm{NCs}$. Reproduced from Protesescu et al. ${ }^{24}$ (f) TEM and (g) high-resolution TEM image of $\mathrm{CsPbBr}_{3}$ NWs. (h) Absorption and $\mathrm{PL}$ spectra of $\mathrm{CsPbBr}_{3} \mathrm{NWs}$; inset shows optical image of a single NWs excited under a laser beam. Reproduced from Zhang et al. 63

monodisperse blue-emitting nanoplatelets and green-emitting nanorods can be prepared in 1 -octadecene at high temperature. ${ }^{51}$ Micro-crystals and NCs comprising layered quasi-2D perovskites in the form of $\mathrm{A}_{2} \mathrm{PbX}_{4}, \mathrm{~A}_{4} \mathrm{PbX}_{6}$ and $\mathrm{A}\left(\mathrm{A}^{\prime}\right)_{2} \mathrm{~Pb}_{2} \mathrm{X}_{7}$ were also reported to be luminescent. ${ }^{52-54}$ Chen et al. ${ }^{55}$ synthesized nano- and micro-sized $\mathrm{MAPbI}_{3}$ perovskite crystals by using mild heating of MAI and $\mathrm{PbI}_{2}$ in different polar solvents. By using solvents with different polarities, $\mathrm{MAPbI}_{3} \mathrm{NCs}$ of different shapes (cubes, rods and hexagons) were obtained. Zhu et al. ${ }^{56}$ reported different morphologies for $\mathrm{MAPbX}_{3}$ NCs with shape-correlated PL by varying the solvents and using different capping ligands. The same group were also the first to report on the instability of perovskite nanostructures under the electron beam in TEM measurements, warning on the correlation of the morphology observed in the TEM with the actual shape of nanoparticles in colloidal dispersions. This was further corroborated by studies of Sichert et al. ${ }^{25}$ who showed that the electron beam could degrade the perovskite nanoplatelets, producing small spherical particles comprising metallic lead or lead bromide.

Several fabrication techniques have been developed for the growth of organic--inorganic perovskite nanowires (NWs) directly 
on substrates. Spina et al. ${ }^{57}$ have shown that NW arrays can be grown in open nanofluidic channels; using this approach, the size, aspect ratio, cross-sectional shape and orientation of NWs could be controlled. Solution processed perovskite films grown on substrates could be converted into NWs via dissolution and recrystallization, as demonstrated by Zhu et al. ${ }^{58}$ Yuan et al. ${ }^{59}$ reported deep blue-luminescent layered lead bromide perovskite microdisks, a few micrometers in size laterally and $15-100 \mathrm{~nm}$-thick with a PLQY reaching 50\%. The same group also reported nanoscale quasi-2D layered perovskites with tunable emissions from 403 to $530 \mathrm{~nm}$ by changing the organic cations used. ${ }^{60}$

\section{Direct synthesis of all-inorganic perovskite NCs}

Perovskite NCs with all-inorganic cations have been receiving significant attention, partly due to their higher stability compared with the hybrid organic-inorganic perovskites. Kovalenko and colleagues $^{24}$ were first to report on caesium lead halide perovskite $\mathrm{NCs}(\mathrm{CsPbX}, \mathrm{X}=\mathrm{Cl}, \mathrm{Br}$ and $\mathrm{I})$, with a high degree of compositional bandgap engineering. They were produced as monodisperse nanocubes with edge lengths of $4-15 \mathrm{~nm}$ using the arrested precipitation of Cs-oleate and $\mathrm{Pb}(\mathrm{II})$-halide precursors in octadecene. It was found that the size of the NCs decreases by decreasing the reaction temperature. Mixed-halide perovskite NCs could be conveniently produced by varying the ratios of precursor salts $\left(\mathrm{PbCl}_{2} / \mathrm{PbBr}_{2}\right.$ or $\left.\mathrm{PbBr}_{2} / \mathrm{PbI}_{2}\right)$. CsPbX 3 NCs crystallized in the cubic phase rather than the orthorhombic or tetragonal phases at high temperatures (Figures $4 \mathrm{a}$ and $\mathrm{b}$ ). The bandgap energies and emission spectra of these NCs were tuneable over the entire visible spectral region of $410-700 \mathrm{~nm}$ by varying the halide composition and the size of the
NCs (Figures $4 \mathrm{c}$ and d). The PL of $\mathrm{CsPbX}_{3}$ NCs was characterized by narrow emission linewidths of $12-42 \mathrm{~nm}$, a wide colour gamut covering up to $140 \%$ of the National Television System Committee color standard, high PLQYs of up to $90 \%$ and PL lifetimes in the range of 1-29 ns (Figure 4e). Later on, by means of a droplet-based microfluidic platform, allowing for online absorption/PL measurements, the same group explored the formation mechanism of these perovskite NCs. ${ }^{61}$ Koolyk et al. ${ }^{62}$ investigated the growth process of caesium lead halide perovskite NCs by time-dependent TEM characterization. They found that the growth kinetics are different for $\mathrm{Cs} \mathrm{PbBr}_{3}$ and $\mathrm{CsPbI}_{3}$, providing a model for each growth process. From the full width at half maximum (FWHM) of the PL spectra, it was observed that $\mathrm{CsPbI}_{3} \mathrm{NCs}$ exhibited size focusing during the first $20 \mathrm{~s}$ of growth, followed by a subsequent size de-focusing (the FWHM increased due to the broadening size distribution). On the contrary, $\mathrm{CsPbBr}_{3} \mathrm{NCs}$ exhibited a de-focusing of the size distribution from the beginning of the reaction and no size focusing occurred within the full reaction time of $40 \mathrm{~s}$. However, a prolonged reaction at higher temperatures leads to the formation of light-emitting single-crystalline $\mathrm{CsPbX}_{3} \quad \mathrm{NWs}$ that crystallize in the orthorhombic phase as reported by Yang and colleagues ${ }^{63}$ (Figures $4 \mathrm{f}-\mathrm{h}$ ). The initially formed cubic NCs transformed into NWs with a few percent of nanosheets as a side product for the prolonged reaction time.

In addition to the hot-injection technique, room-temperature reprecipitation methods have also been used for the synthesis of $\mathrm{CsPX}_{3}$ NCs of different morphologies. For instance, Huang et al. ${ }^{49}$ reported the emulsion-based synthesis of perovskite NCs (both hybrid and all-inorganic) at room temperature. In a recent report Li et al. ${ }^{64}$ a

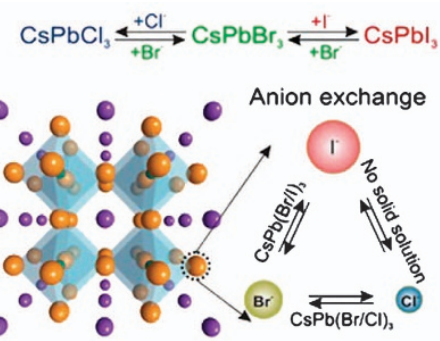

$$
\begin{gathered}
\text { Precursors: } \\
\mathrm{Cl}: \mathrm{PbCl}_{2}, \mathrm{OAmCl}, \mathrm{MeMgCl} \\
\mathrm{Br}: \mathrm{PbBr}_{2}, \mathrm{OAmBr}, \mathrm{MeMgBr} \\
\text { l: } \mathrm{Pbl}_{2}, \mathrm{OAml}, \mathrm{MeMgl}
\end{gathered}
$$

b

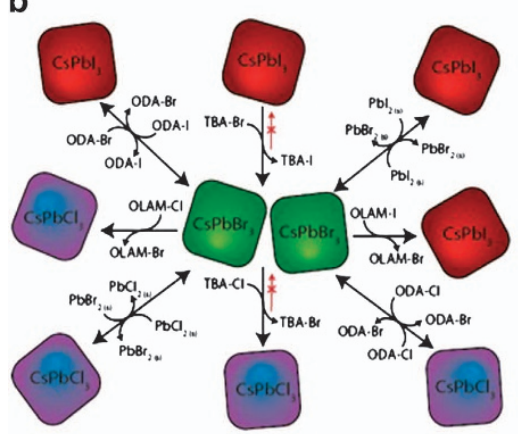

C
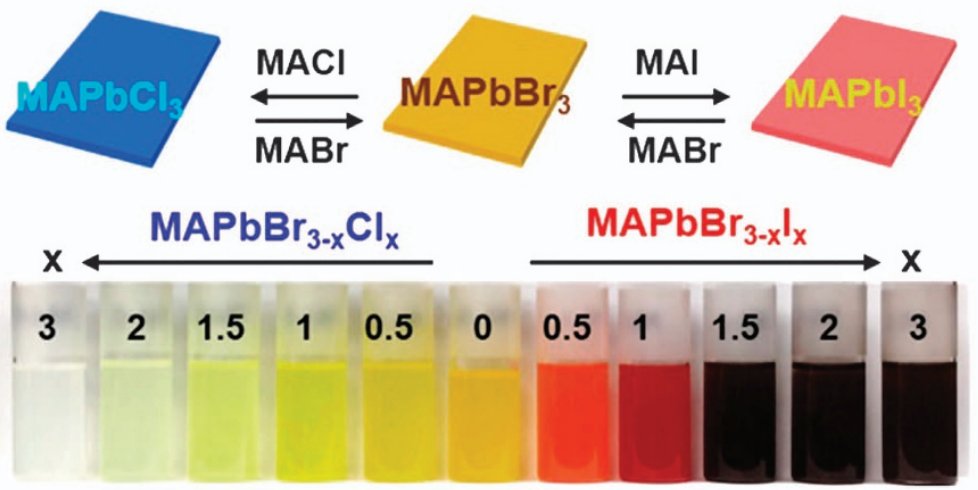

d

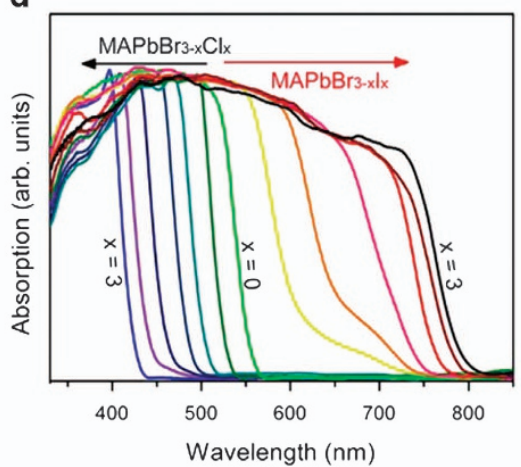

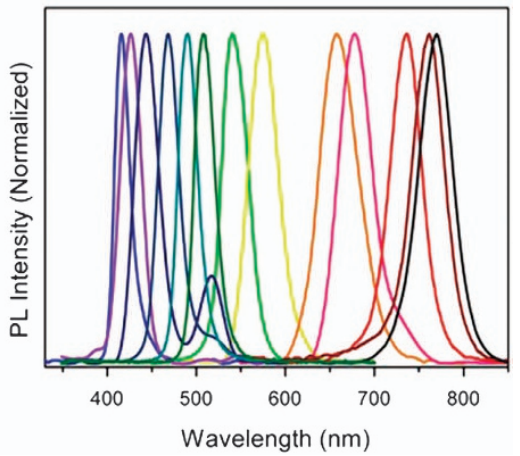

Figure 5 (a) Schematics of possible anion-exchange raeactions within the crystal structure of $\mathrm{CsPbX}_{3}$ crystal lattice, with indication of suitable reagents. Reproduced from Nedelcu et al. ${ }^{68}$ (b) Different routes and precursors for $\mathrm{CsPbX}_{3}(\mathrm{X}=\mathrm{Cl}, \mathrm{Br}, \mathrm{I})$ ion exchange. Reproduced from Akkerman et al.69 (c) Photographs of ion-exchanged, mixed-halide $\mathrm{MAPbBr}_{3-x} \mathrm{Cl}_{x}$ and $\mathrm{MAPbBr}_{3-x} \mathrm{I}_{x} \mathrm{NCs}$ under room light. (d) UV-visible and $\mathrm{PL}$ spectra of $\mathrm{MAPbBr}_{3-x} \mathrm{Cl}_{x}$ and $\mathrm{MAPbBr}_{3-x} \mathrm{I}_{x} \mathrm{NC}$ films. Reproduced from Jang et al. ${ }^{70}$ 
showed that $\mathrm{CsPbX}_{3} \mathrm{NCs}$ can be synthesized at room temperature, similar to the LARP method used for the $\mathrm{MAPbX}_{3}$ system. Manna and colleagues $^{65}$ have demonstrated the synthesis of quantum-confined $\mathrm{CsPBr}_{3}$ nanoplatelets at room temperature. They have shown that anisotropic growth leads to the formation of nanoplatelets at room temperature through the injection of acetone in a mixture of precursor. The low growth temperature facilitates the control of the plate thickness down to three monolayers. In addition, it was shown by Sun et al. ${ }^{26}$ that the shape of the NCs could be controlled using different ligand molecules. In this regard, $\mathrm{CsPbX}_{3} \mathrm{NCs}$ of different shapes such as spherical dots, nanocubes, nanorods and nanoplatelets were prepared by using different organic acids and amine ligands; however, the growth mechanism was not discussed. The roomtemperature solution-phase synthesis of nanoplatelets can be easily scaled up as shown by $\mathrm{Yu}$ and colleagues. ${ }^{66}$ Driven by the wish to replace the toxic lead, Jellicoe et al. synthesized $\mathrm{CsSnX}_{3}$ perovskite NCs, with optical properties tunable both by quantum confinement and halide composition. ${ }^{67}$ The overview of reported studies clearly suggests that reaction temperature and the choice of ligands play a vital role in determining the dimensionality and size of colloidal metal halide perovskite NCs. In general, low reaction temperatures and high ligand concentrations favor anisotropic growth, mainly producing nanoplatelets with controlled thickness and lateral sizes.

Synthesis of perovskite NCs through halide ion exchange reactions A post-preparative halide ion exchange on perovskite NCs provides an additional means to modify their composition and thus the optical properties, while preserving their size and morphology. Kovalenko and colleagues $^{68}$ and Manna and colleagues ${ }^{69}$ have almost simultaneously reported this approach for $\mathrm{CsPbX}_{3}(\mathrm{X}=\mathrm{Cl}, \mathrm{Br}, \mathrm{I}) \mathrm{NC}$ systems, tuning their emission over the spectral range of $410-700 \mathrm{~nm}$ with high PLQYs of $20-80 \%$ (Figures $5 \mathrm{a}$ and $\mathrm{b}$ ). Such anion exchange was also reported for hybrid $\mathrm{MAPbBr}_{3} \mathrm{NCs}$, which were synthesized in an approach similar to that of Pérez-Prieto and colleagues, ${ }^{30}$ and subsequently mixed with methyl ammonium halide ( $\mathrm{Cl}$ or $\mathrm{I}$ ) to produce $\mathrm{MAPbBr}_{3-x} \mathrm{Cl}_{x}$ or $\mathrm{MAPbBr}_{3-x} \mathrm{I}_{x}$ NCs (Figure 5c). ${ }^{70}$ The UV-visible absorption and PL emission of both colloidal solutions and films confirmed the composition control of the exchange reaction, demonstrating band gap tuning over the whole visible range (Figure 5d).The anion exchange is also possible in the solid phase as demonstrated by Yang and colleagues. ${ }^{71}$ Following a solution-phase growth of $\mathrm{MAPbBr}_{3}$ nanorod arrays, they were subsequently converted to $\mathrm{MAPbI}_{3}$ of similar morphology via annealing at $140-150{ }^{\circ} \mathrm{C}$ in MAI vapour. The $\mathrm{MAPbBr}_{3}$ nanorod array exhibited a green electroluminescence at $533 \mathrm{~nm}$ with a FWHM of $26 \mathrm{~nm}$, whereas the $\mathrm{MAPbI}_{3}$ emitted at $782 \mathrm{~nm}$.

\section{OPTICAL PROPERTIES OF PEROVSKITE NCs}

Metal halide perovskite NCs exhibit intriguing optical properties, such as high PLQYs and a narrow emission spectrum, which is tunable from the near UV to near-IR by varying their constituent elements, size or dimensions. Initially, the field focused on the rapid advancement in the synthesis of NCs and their integration into devices and applications. Studies aimed at the understanding of the nature of photoexcitations and origin of PL in perovskite NCs have consequently lagged behind. ${ }^{5,72,73}$ This understanding, however, is crucial for improvement of device efficiencies and there are currently many intensive investigations through both experimental (temperaturedependent PL measurements) and theoretical studies. ${ }^{72,74,75}$ However, most of the reported studies were focused on bulk perovskite films and it would be interesting to perform future studies using films made out of NCs. The photoexcitation of perovskites can lead to the formation of both free charge carriers and excitons, which then recombine to emit photons with energies dependent on the respective bandgap of the perovskites. ${ }^{76}$ Although the question over the dominant species is still under extensive investigation, it is believed that free charge carriers are prevalent in MA-based perovskite films, leading to the reported high values of photovoltaic efficiency, as exciton dissociation is thus unnecessary. This was shown, for example, in a recent theoretical study by Even et al. ${ }^{77}$ who claimed that free carriers are photoexcited at room temperature, whereas Wannier-Mott excitons are dominant at low temperatures. Measurements showing narrow band-edge emission with a very small Stokes shift of a few $\mathrm{meV}$ and bimolecular recombination dynamics support the notion that recombination of free electrons and holes is the origin of PL in perovskite thin films at room temperature. ${ }^{5,78}$ Temperature-dependent PL measurements show that this is not necessarily the case at low temperatures, where the exciton-binding energy is likely to increase and excitons are much more prevalent. ${ }^{72-74}$ The composition of perovskites has a large impact on the bulk optical properties, but so does the size of crystals, once they are shrunk down to exhibit quantum confinement. ${ }^{25,46}$ Not only size, but also dimensionality has a role, as, for example, $2 \mathrm{D}$ platelets will have a binding energy of four times the bulk value in the ideal case. ${ }^{79}$ In the following, we discuss the quantum confinement in perovskites and provide recent insights into the optical properties of metal halide perovskite NCs.

\section{Quantum confinement in perovskite NCs}

As already mentioned above, the optical properties of perovskite NCs strongly depend not only on their constituent metal and halide ions, but also on their dimensionality and size. Quantum confinement effects have been widely investigated in conventional semiconductor nanomaterials of all dimensionalities. ${ }^{80-82}$ Optical properties of thin film (2D) perovskites have been studied since the late $80 \mathrm{~s},{ }^{83,84}$ whereas the latest developments in the size-controlled synthesis of perovskite NCs have enabled detailed investigations of quantum confinement effects in NCs. ${ }^{25,29,46,50,85-87}$ Sichert et al. ${ }^{25}$ showed that the perovskite crystal structure can be progressively reduced in a lateral dimension, yielding quasi-2D and ultimately $2 \mathrm{D}$ nanoplatelets with a thickness of only a single unit cell (Figure 6a). By varying the ratio of two organic cations, the commonly used $\mathrm{MA}$ and the significantly longer octylammonium, the thickness of platelets could be controlled, resulting in pronounced quantum size effects in $\mathrm{MAPbBr}_{3}$ nanoplatelets (Figures $6 a$ and $b)^{25}$ with an integer amount of layers varying from 1 to 7 (Figure 6b). The authors corroborated their experimental findings with quantum-mechanical calculations, showing good agreement with the measured excitonic transition energy of nanoplatelets. It was found out that for these highly confined 2D systems, the exciton binding energy reaches several hundreds of $\mathrm{meV}$, similar to values for bulk layered perovskites. ${ }^{43,88,89}$ Thus, it is possible to tune the optical properties of perovskite nanoplatelets by controlling the number of layers. Similar effects have been also reported by other groups. ${ }^{32,46,51,59}$ For instance, Snaith and colleagues ${ }^{90}$ used the same approach to demonstrate tunable PL from $\mathrm{MAPbI}_{3} \mathrm{NCs}$. The increase of octylamine content in the reaction medium resulted similarly in the formation of nanoplatelets.

Friend and colleagues ${ }^{85}$ observed size-dependent photon emission from $\mathrm{MAPbBr}_{3} \mathrm{NCs}$ embedded in an organic matrix, where the NC size and thus their PL peak could be tuned by varying the concentration of the precursors. The PL peak gradually shifted to higher energies with decreasing particle size. Hassan et al. ${ }^{86}$ showed tunable PL from lead halide perovskite NCs by varying the number of layers, starting 
a

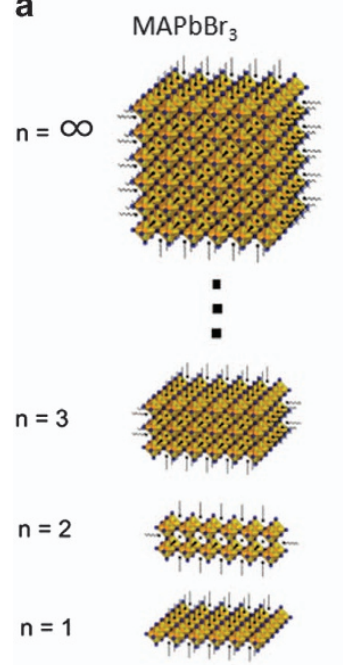

b

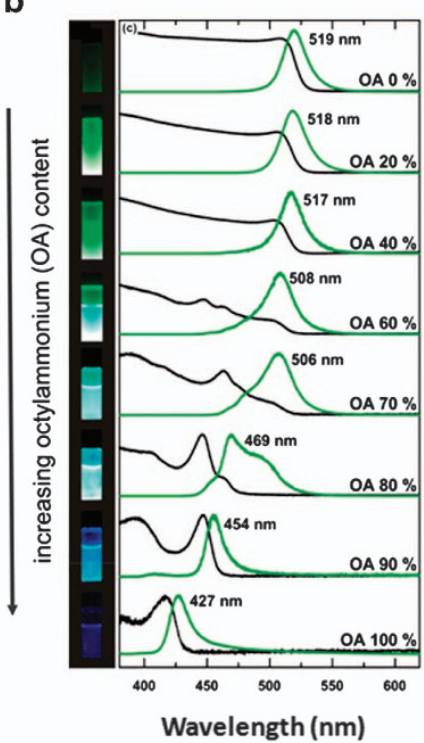

C

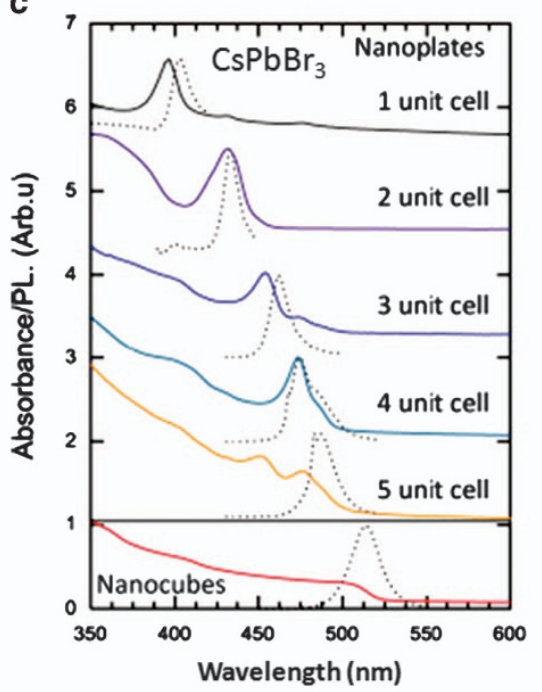

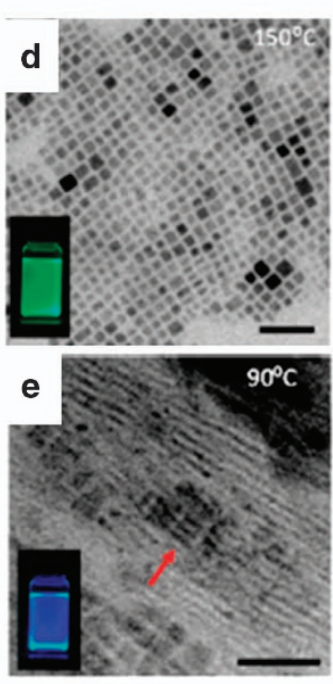

Figure 6 (a) Schematic representation of $\mathrm{CH}_{3} \mathrm{NH}_{3} \mathrm{PbBr}_{3}$ nanoplatelets with different number of layers $(n=1,2,3$ and $\infty)$. The number of layers decreased with increasing octylamine $(\mathrm{OA})$ content in the reaction mixture. (b) UV-visible and $\mathrm{PL}$ spectra of $\mathrm{CH}_{3} \mathrm{NH}_{3} \mathrm{PbBr}_{3}$ perovskite films prepared from the colloidal NC suspensions synthesized using different amounts of OA (0-100\%), with photographs of the respective solutions under UV light. Adapted from Sichert et al. $^{25}$ (c) UV-visible (solid lines) and PL (dashed lines) spectra of $\mathrm{CsPbBr}_{3}$ nanocubes and nanoplatelets made of 1-5 unit cells. (d, e) TEM images of $\mathrm{CsPbBr}_{3} \mathrm{NCs}$ synthesized at $150^{\circ} \mathrm{C}$ (green emitting nanocubes) and $90{ }^{\circ} \mathrm{C}$ (blue emitting thin nanoplatelets), respectively. The insets show photographs of the respective solutions under UV light. Reproduced from Bekenstein et al. ${ }^{92}$

from pre-synthesized NC seeds by a controlled addition of alkyl ammonium halide. As shown in Figure 7 a, the resulting $\mathrm{MAPbI}_{3} \mathrm{NCs}$ emit green, orange and red colors for 1, 2 and 3 layers, respectively. Sapori et al. ${ }^{87}$ performed a theoretical study on the quantum confinement in 2D perovskite NCs composed of different cations and halide ions. Their results, showing an increase of the band gap as the number of layers in the nanoplatelets decreases, are in good agreement with the experimental results discussed above (Figure 7b).

In addition to solution-based colloidal synthesis, NCs of different sizes were grown on solid substrates. ${ }^{85}$ Yang and colleagues ${ }^{91}$ have shown that atomically thin single-crystalline $2 \mathrm{D}$ organic-inorganic perovskites of square-shaped morphology can be directly grown on silicon substrates by drop casting a very dilute precursor solution followed by mild heating (Figures $7 \mathrm{c}-\mathrm{e}$ ). AFM images showed that the prepared $2 \mathrm{D}\left(\mathrm{C}_{4} \mathrm{H}_{9} \mathrm{NH}_{3}\right)_{2} \mathrm{PbBr}_{4}$ sheets exhibit single to few unit cell thicknesses due to the stacking of layers through van der Waals interactions between ligands (Figure 7e). The stacking effect had only a minor effect on the optical properties as stacks of varying thickness exhibited nearly the same emission wavelength $(\sim 405 \mathrm{~nm})$. This emission was still considerably blue shifted with respect to the PL peak of the bulk perovskite due to the quantum confinement effect.

Quantum confinement effects have also been reported for all-inorganic $\mathrm{CsPbX}_{3}$ NCs. Kovalenko and colleagues ${ }^{24}$ reported size-dependent PL emission from square-shaped $\mathrm{CsPbBr}_{3} \mathrm{NCs}$, in which the PL peak gradually blue shifted from 512 to $460 \mathrm{~nm}$ as the edge size decreased from 11.8 to $3.8 \mathrm{~nm}$. Alivisatos and colleagues ${ }^{92}$ reported the synthesis of quantum-confined highly fluorescent (PLQY $84 \%) \mathrm{CsPbX}_{3}$ perovskite nanoplatelets (Figures $6 \mathrm{c}-\mathrm{e}$ ). They showed that the thickness of $\mathrm{CsPbBr}_{3}$ nanoplatelets can be tuned from 1 to 5 unit cells thick by changing the reaction temperature, with the monolayer platelets emitting at $400 \mathrm{~nm}$ (Figure 6e), whereas the bulk-like crystals emitted at $520 \mathrm{~nm}$ (Figure 6d). Similarly, Manna and colleagues ${ }^{65}$ have shown that the thickness of $\mathrm{CsPbBr}_{3}$ platelets could be precisely tuned between 3 and 5 monolayers, keeping a narrow emission and a strong blue shift of the PL peak compared with that of bulk $\mathrm{CsPbBr}_{3}$. In addition, they have also shown that the lateral size of the quantum-confined $\mathrm{CsPbBr}_{3}$ nanoplatelets (thickness $\sim 3 \mathrm{~nm}$ ) can be controlled up to the micrometer range by varying the ratio of shorter ligands (octanoic acid and octylamine) to longer ligands (oleic acid and oleylamine), while maintaining their thickness and, to a large degree, the optical properties. ${ }^{93}$

\section{Single-particle emission of perovskite NCs}

Most of the studies discussed above have been performed on ensembles of perovskite NCs. However, single-particle measurements are sometimes necessary, in order to obtain accurate correlations between their optical properties and size/morphology. ${ }^{27,71,94-99}$ Tian et al. ${ }^{100}$ provided direct visualization of the photogenerated carrier diffusion in single $\mathrm{MAPbBr}$ and $\mathrm{MAPbI}_{3} \mathrm{NWs}$ and nanoplates using time-resolved PL-scanning microscopy (Figures 8a-e). This technique is based on the photoexcitation of a single particle at one specific position and subsequently scanning the substrate at different positions by time-resolved PL as a function of delay time. The diffusion lengths, averaged for holes and electrons, for $\mathrm{MAPbI}_{3}$ and $\mathrm{MAPbBr}_{3}$ were found to be $14.0 \pm 5.1$ and $6.0 \pm 1.6 \mu \mathrm{m}$, respectively.

Another interesting phenomenon that has been addressed by single-particle studies of perovskite NCs is emission blinking. ${ }^{96-98}$ Fluorescence intermittency (blinking) has been widely observed in metal-chalcogenide quantum dots, which can remain in so-called 'dark states' for significant times, ranging from microseconds up to several minutes. ${ }^{101,102}$ Blinking is generally thought to result from light-driven charging (or ionization) and discharging of the colloidal NC core or of surface electron traps on photoexcitation. The neutral semiconductor NCs appear bright when photoexcited electron-hole pairs recombine, emitting photons. However, charging of NCs can promote Auger recombination and trap states can bind charge 
a

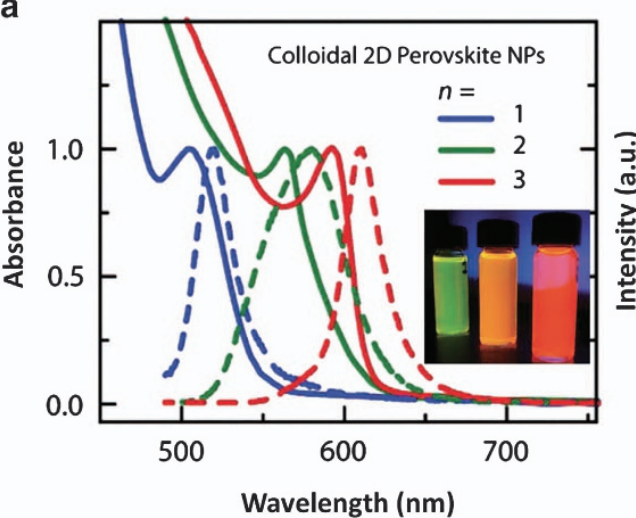

b

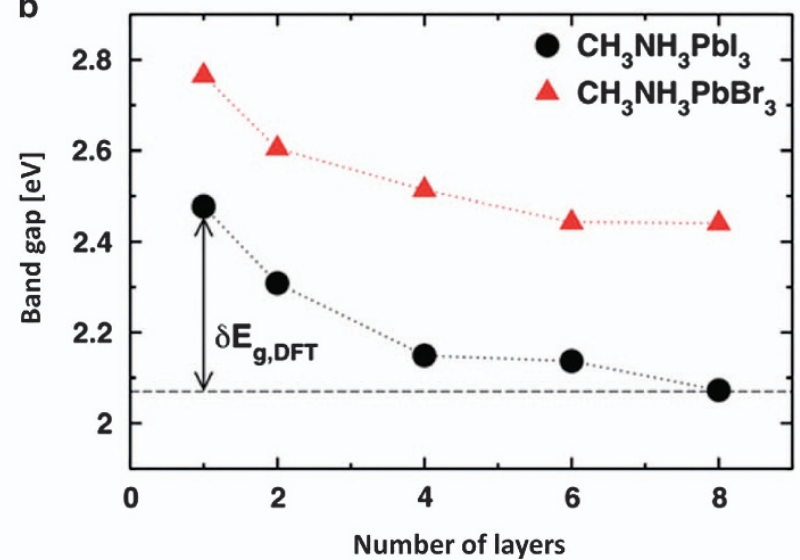

C

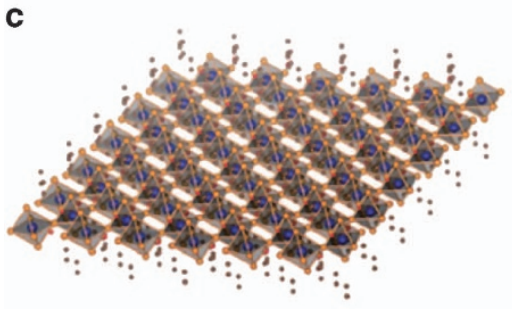

$\left(\mathrm{C}_{4} \mathrm{H}_{9} \mathrm{NH}_{3}\right)_{2} \mathrm{PbBr}_{4}$
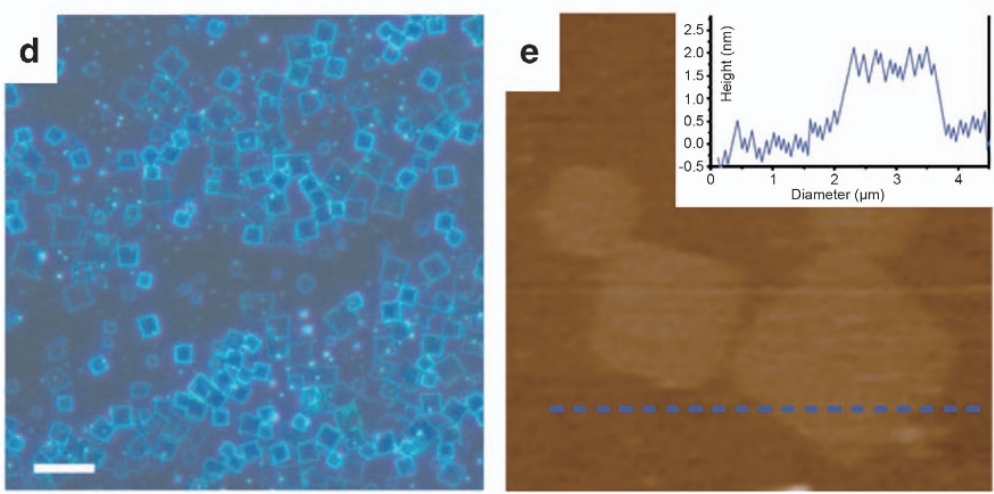

Figure 7 (a) UV-visible absorption (solid lines) and PL spectra (dotted lines) of $2 \mathrm{D} \mathrm{CH}_{3} \mathrm{NH}_{3} \mathrm{Pbl}_{3} \mathrm{NCs}$ consisting of $n=1,2$ and 3 layers. Reproduced from Hassan et al. 86 (b) Bandgap dependence on the number of layers in nanoplatelets of $\mathrm{CH}_{3} \mathrm{NH}_{3} \mathrm{PbX}_{3}(\mathrm{X}=\mathrm{I}, \mathrm{Br})$, obtained from theoretical calculations. Reproduced from Saprori et al. ${ }^{87}$ (c) Structural representation of a monolayer $\left(\mathrm{C}_{4} \mathrm{H}_{9} \mathrm{NH}_{3}\right)_{2} \mathrm{PbBr}_{4}$ perovskite. (d) Optical microscopy image of such 2D perovskite platelets grown on substrates. Scale bar: $10 \mu \mathrm{m}$. (e) AFM image of single layer perovskite platelets. The inset shows the height profile with the thickness of $1.6 \mathrm{~nm}$. Reproduced from Dou et al..$^{91}$

carriers, preventing recombination, all of which has been considered to contribute to blinking. ${ }^{102-104}$ Tian et al..$^{98}$ observed PL blinking from $\mathrm{MAPbI}_{3}$ nanorods (Figures $8 \mathrm{~h}-\mathrm{j}$ ) and attributed it to photo-induced activation and de-activation of PL quenching sites, presumably present at the ends of the rods where formation of geometrical and chemical defects are most likely to occur. Similarly, blinking was also observed in single perovskite $\mathrm{MAPbBr}_{3} \mathrm{NCs}$ and attributed to the presence of charge trapping surface states. ${ }^{97}$ Blinking was also seen in all-inorganic $\mathrm{CsPbX}_{3}$ perovskite NCs (Figure 8f). ${ }^{94-96}$ It was observed that the FWHM of the PL of single $\mathrm{CsPbBr}_{3} \mathrm{NCs}$ is nearly the same as that of the ensemble PL spectrum, indicating that the size distribution does not alter their optical properties significantly. This was ascribed to the fact that the charge carriers are only weakly Bohr radius confined for the particle size studied $(11 \mathrm{~nm})$, which exceeds the exciton of $\mathrm{CsPbBr}_{3}{ }^{96}$ As shown in Figure 8g, individual $\mathrm{CsPBr}_{3} \mathrm{NCs}$ show fast recovery times from the off- to on-state, with the on-states dominating. However, eliminating the blinking behaviour in perovskite NCs is crucial for advancing their applications for LEDs and in biosystems. Over the years, various strategies have been proposed to eliminate the blinking in conventional semiconductor NCs. One of the most widely employed solutions is based on suppression of ionization by growing a thick semiconductor shell on the NC surface. Being a relatively new field, there have not been any studies yet on reducing blinking in perovskites. Some studies have shown that $\mathrm{CsPbX}_{3}$ (where $\mathrm{X}=\mathrm{Cl} / \mathrm{Br}$ ) NCs seem to be less prone to blinking and display stable emission at low temperatures. ${ }^{105}$
Nevertheless, it seems as the problems associated with photostability and blinking of perovskite NCs are largely similar to those of conventional semiconductor quantum dots. Therefore, resolving the issue by applying the methodologies developed over the years for semiconductor NCs is of a great relevance.

Amplified spontaneous emission and lasing with perovskite NCs Perovskites are considered an attractive class of materials for lasing, owing to their large absorption coefficients, slow Auger recombination and high optical gain. ${ }^{10,37}$ Xing et al. ${ }^{10}$ observed a stable amplified spontaneous emission (ASE) at low thresholds from solution processed thin films comprising MA-based perovskites. The wavelength of ASE could be tuned across the whole visible and near-IR spectral range by varying the halide ion content of perovskites, as for the regular PL emission. ${ }^{10}$ Despite the ease of fabrication of bulk perovskite films by solution processing, they exhibit relatively low PLQYs, limiting further applications in this respect. High PLQY is one of the main advantages of the colloidal perovskite NCs, prompting researchers to perform intensive investigations for their use as optical gain media for lasing. ${ }^{13,34,36,37,106-108}$ Zhu et al. ${ }^{13}$ have demonstrated wavelengthtunable lasing from single-crystalline organic-inorganic lead perovskite NWs with low thresholds $\left(\sim 220 \mathrm{~nJ} \mathrm{~cm}^{-2}\right)$ and high quality factors of $Q \sim 3600$ (Figures $9 a-c$ ). The narrowing of the FWHM in the PL spectra by two orders of magnitude above an excitation fluence threshold presented a clear sign of lasing (Figure 9b). Time-resolved fluorescence analysis indicated that charge carrier trapping was 
a

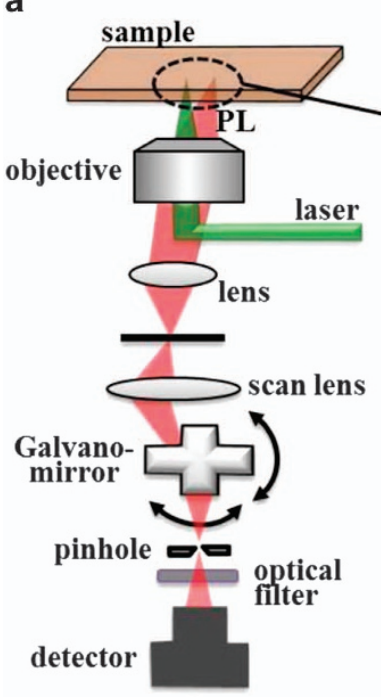

b

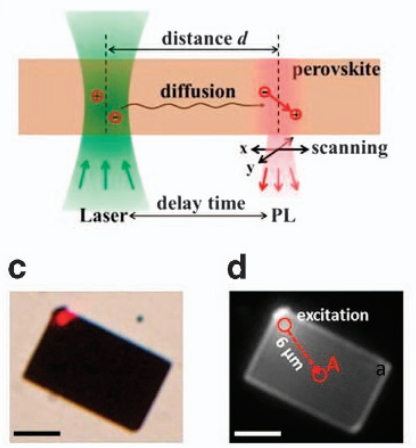

e

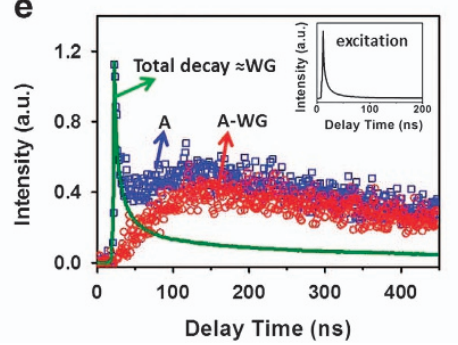

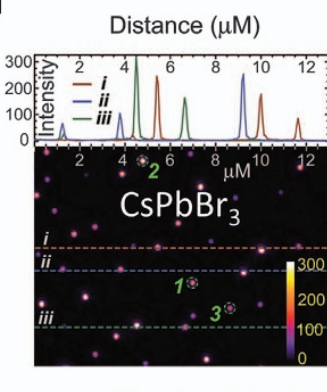

Wavelength $(\mathrm{nm})$

h

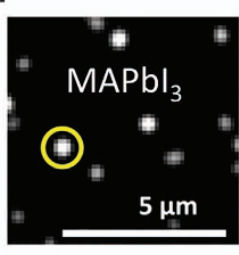

g

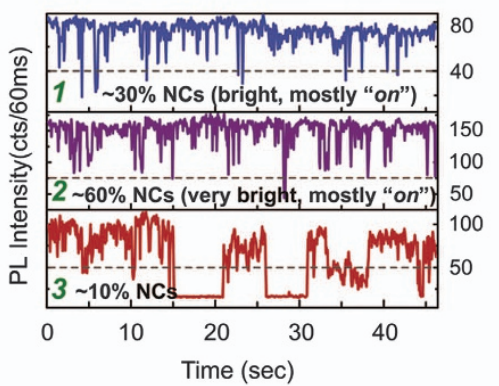

j
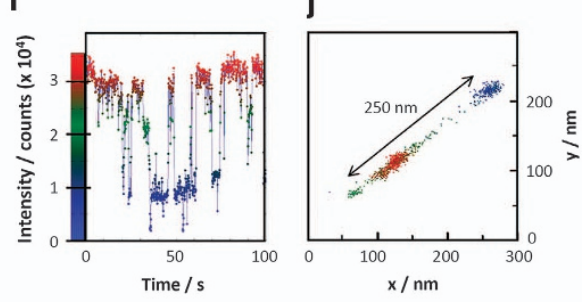

Figure 8 (a) Schematic illustration of fluorescence scanning confocal microscopy set-up for visualizations of the charge carrier diffusion in perovskite plates. (b) Schematic representation of the charge carrier excitation and probing the diffusion, and recombination processes. (c) Optical (the red spot indicates the laser excitation spot) and (d) $\mathrm{PL}$ intensity images of a $\mathrm{CH}_{3} \mathrm{NH}_{3} \mathrm{Pbl}_{3}$ plate (' $\mathrm{A}$ ' indicates the position where the PL kinetics is probed with respect to time delay). Scale bar: $5 \mu \mathrm{m}$. (e) PL kinetics obtained from the position 'A' (blue squares). Solid green curve is PL decay collected from the entire plate, which was used to estimate the wave-guided component for subtraction. Red curve represents the net kinetics at position $A$ after subtracting the wave-guided contribution. The inset shows the PL kinetics collected from excitation site. Reproduced from Tian et al. ${ }^{100}$ (f) PL image and intensity line profiles of individual $\mathrm{CsPbBr}_{3} \mathrm{NCs}$. (g) PL intensity fluctuation versus time for three typical single NCs marked in the part (f). Reproduced from Swarnkar et al. ${ }^{96}$ (h) PL image of individual $\mathrm{CH}_{3} \mathrm{NH}_{3} \mathrm{Pbl}_{3} \mathrm{NCs}$. (i) $\mathrm{PL}$ intensity fluctuation of a typical $\mathrm{CH}_{3} \mathrm{NH}_{3} \mathrm{Pbl} 3 \mathrm{NC}$ vs time and (j) the positions of corresponding emission localization. Reproduced from Tian et al. ${ }^{98}$

a

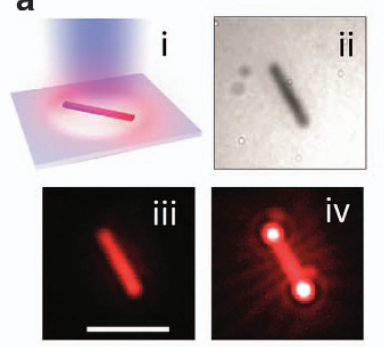

b

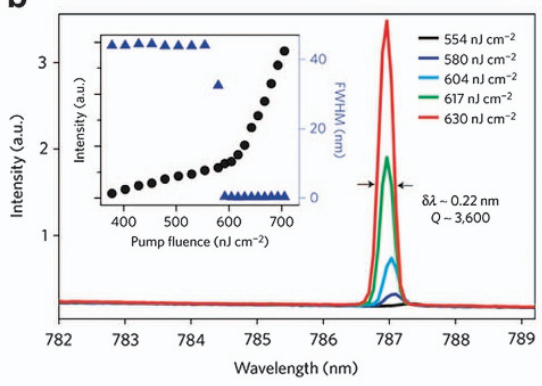

f

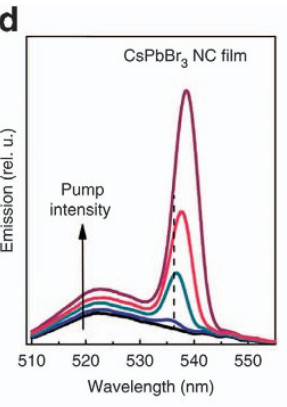

Energy (eV)

C

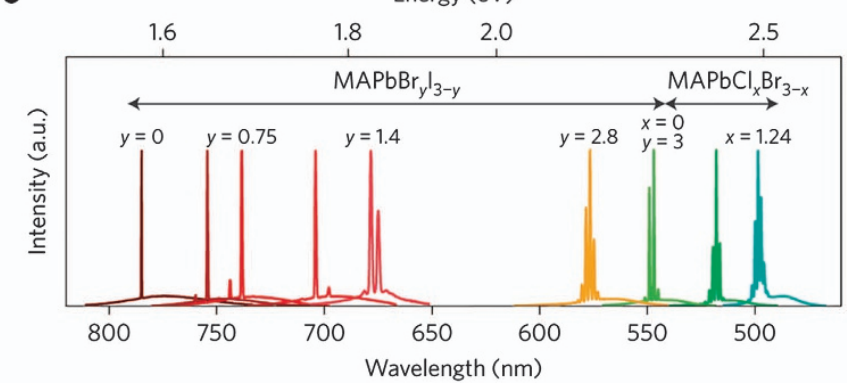

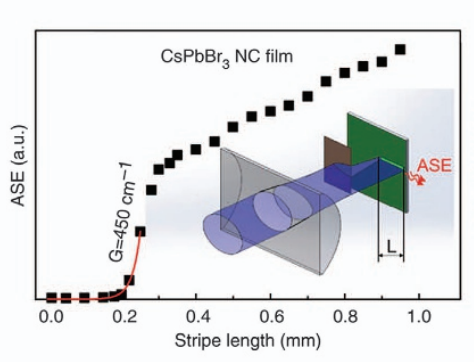

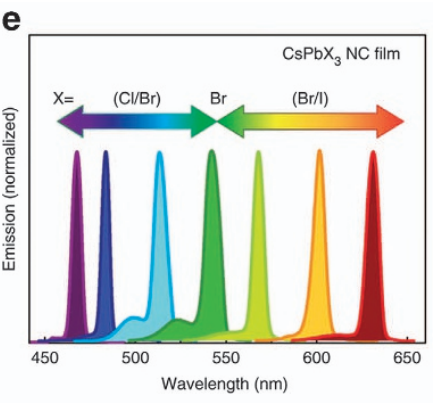

g

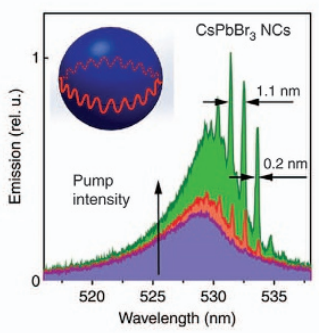

Figure 9 (a) Illustration of a single $\mathrm{CH}_{3} \mathrm{NH}_{3} \mathrm{Pbl}_{3} \mathrm{NW}$ on $\mathrm{SiO}_{2}$ substrate pumped under a laser excitation: (i) optical image (ii) and $\mathrm{PL}$ image of this $\mathrm{NW}$ below (iii) and above (iv) threshold (scale bar: $10 \mu \mathrm{m}$ ). (b) $\mathrm{PL}$ spectra of a $\mathrm{CH}_{3} \mathrm{NH}_{3} \mathrm{~Pb} \mathrm{I}_{3} \mathrm{NW}$ at different pump fluences. The inset shows the integrated PL intensity and FWHM as a function of pump fluences. (c) Tunable lasing emission wavelengths from MA-based perovskite NWs made of mixed lead halides. Reproduced from Zhu et al. ${ }^{13}$ (d) PL spectra of $\mathrm{CsPbBr}_{3} \mathrm{NCs}$ at different pump fluences, showing ASE at higher fluences. (e) Tunable ASE from caesium

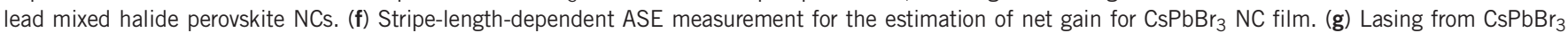
NC film: Evolution of PL spectra into whispering-gallery-mode lasing with increasing pump fluence in a film covered on top of microsphere resonator. Reproduced from Yakunin et al. ${ }^{37}$ 

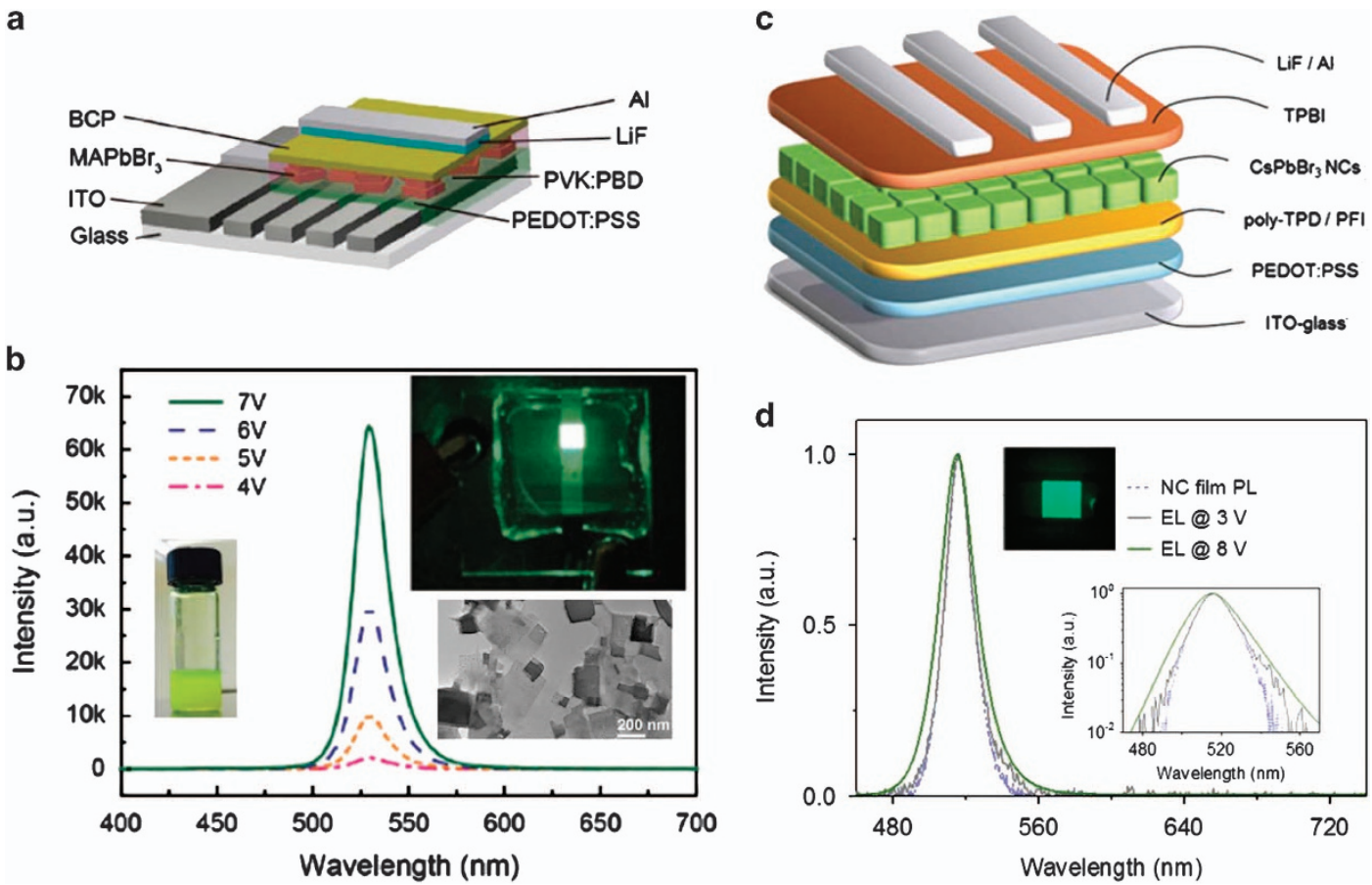

Figure 10 (a) Schematic illustration of the device architecture used for the fabrication of LEDs using $\mathrm{CH}_{3} \mathrm{NH}_{3} \mathrm{PbBr}_{3}$ perovskite nanoplatelets as an emitter layer. (b) Electroluminescence spectrum obtained from a perovskite nanoplatelets-based LED at different applied voltages. The insets show a photograph of working LED and a TEM image of nanoplatelets employed. Reproduced from Lin et al. ${ }^{32}$ (c) Device architecture used for the fabrication of LEDs using $\mathrm{CsPbBr} r_{3} \mathrm{NCs}$ as an emitter layer. (d) Emission spectrum of the $\mathrm{CsPbBr}_{3} \mathrm{NC}$ film and electroluminescence spectrum of the CsPbBr ${ }_{3}$-based LED fabricated using the device structure shown in c. Insets show a photograph of working LED and the corresponding log-scale electroluminescence spectra. Reproduced from Zhang et al. ${ }^{38}$

minimal, with a lasing QY of nearly 100\%. Interestingly, the NWs emitted nearly uniformly across their whole length at low pump fluences (Figure 9a (iii)), whereas the emission predominantly came from the ends when excited above the lasing threshold (Figure 9a (iv)). The stability of NWs was low, as they degraded under continuous illumination after a few tens of minutes, likely to be due to a build-up of heat. Fu et al. ${ }^{106}$ have found that formamidinium lead halide perovskite NWs exhibit higher thermal stability under continuous pulsed excitation compared with MA-based perovskite NWs. Xing et al. ${ }^{108}$ reported lasing from hybrid perovskite NWs produced by vapour-phase synthesis. Two-photon excitation can also lead to lasing in perovskite wires at low thresholds $\left(674 \mu \mathrm{J} \mathrm{cm}^{-2}\right)$, with quality factors of $Q \sim 682$. Other morphologies of hybrid perovskites such as microdisks have also been shown to produce efficient optical gain. ${ }^{107,109}$

All-inorganic perovskite NCs, with high PLQYs and greater stability, have also been explored as a potential optical gain medium. Kovalenko and colleagues $^{37}$ demonstrated wavelength tunable low-threshold ASE and lasing from colloidal caesium lead halide perovskite NCs at room temperature (Figures 9d-g). The lasing threshold and the modal net gain (estimated from the variable stripe-length experiment shown in Figure 9f) were found to be $5 \pm 1 \mu \mathrm{cm}^{-2}$ and $450 \pm 30 \mathrm{~cm}^{-1}$, respectively. The authors also reported whispering-gallery-mode lasing on silica microsphere resonators coated with $\mathrm{CsPbBr}_{3} \mathrm{NCs}$ (Figure 9g), whereas thin films of the NCs showed random lasing. ${ }^{37}$ Suspensions of such NCs showed ASE and lasing when infiltrated into a capillary tube. ${ }^{110}$ Wang et al. ${ }^{36}$ demonstrated low-threshold one-, two- and multi-photon pumped ASE from $9 \mathrm{~nm} \mathrm{CsPbBr}_{3} \mathrm{NCs}$ with large two-photon absorption cross-sections. These studies indicate that both hybrid and inorganic perovskite NCs are promising for lowthreshold laser devices.

\section{APPLICATIONS OF PEROVSKITE NCs \\ Perovskite NCs in LEDs}

Tunable emission with high PLQY, low cost and solution processability of perovskite NCs make them attractive for use in LEDs. ${ }^{9}$ Metal halide perovskite-based LEDs have been fabricated both by solution processing and chemical vapor deposition methods. Perovskite materials were incorporated into LEDs functioning at liquid nitrogen temperature back in $90 \mathrm{~s}^{111}$ and room temperature-working bright LEDs were fabricated by solution processing of hybrid perovskites by Tan et al. ${ }^{9}$ In this device, emitting in the IR, a solution-processed $\mathrm{CH}_{3} \mathrm{NH}_{3} \mathrm{PbI}_{3-x} \mathrm{Cl}_{x}$ perovskite layer was sandwiched between $\mathrm{TiO}_{2}$ and poly(9,9-dioctylfluorene) (F8) layers for effective radiate recombination of electrons and holes in the perovskite layer. The device produced a radiance of $13.2 \mathrm{~W} \mathrm{sr}^{-1} \mathrm{~m}^{-2}$ at a current density of $363 \mathrm{~mA} \mathrm{~cm}^{-2}$, with internal and external quantum efficiencies of $3.4 \%$ and $0.76 \%$, respectively. Using the bromide perovskite, an LED operating in the green was fabricated with an architecture of ITO/ PEDOT:PSS $/ \mathrm{CH}_{3} \mathrm{NH}_{3} \mathrm{PbBr}_{3} / \mathrm{F} 8 / \mathrm{Ca} / \mathrm{Ag}$, producing a luminance of $364 \mathrm{~cd} \mathrm{~m}^{-2}$ at a current density of $123 \mathrm{~mA} \mathrm{~cm}^{-2}$. LEDs based on perovskite NCs, which have significantly higher quantum efficiencies than bulk perovskite films, are expected to exhibit far superior performance. ${ }^{32,38}$ Gao and colleagues ${ }^{32}$ reported bright green LEDs using $\mathrm{MAPbBr}_{3}$ nanoplatelets in a device made of glass/ITO/ PEDOT: PSS/ $\mathrm{H}_{3} \mathrm{NH}_{3} \mathrm{PbBr}_{3}-\mathrm{PVK}: \mathrm{PBD} / \mathrm{BCP}$ (bathocuproine, $50 \mathrm{~nm}$ )/LIF/Al (Figures 10a and $\mathrm{b}$ ). Here, the PEDOT:PSS acts as the hole-injection layer, the PVK:PBD (poly(9-vinylcarbazole):2-(4-biphenylyl)-5phenyl-1,3,4-oxadiazole) as the bipolar host and the BCP as the 

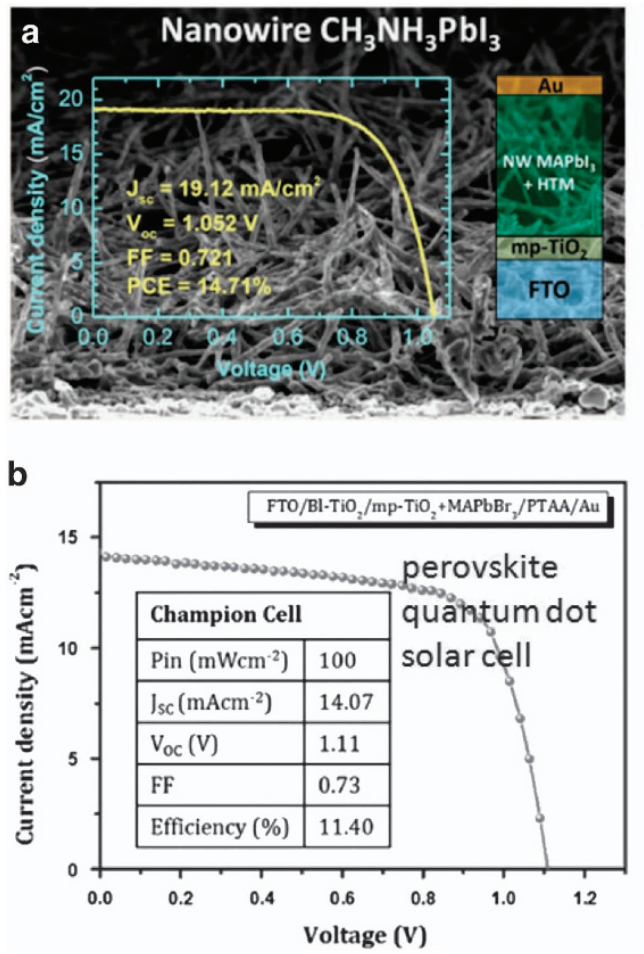
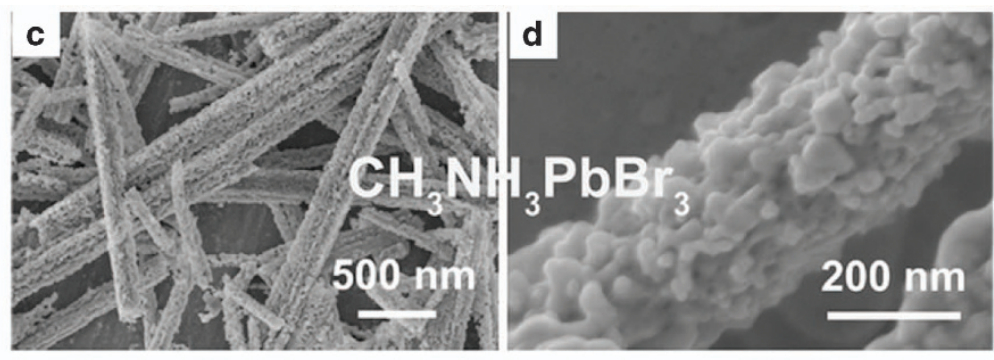

High-Performance Visible-Light Photodetector using Perovskite Nanowires

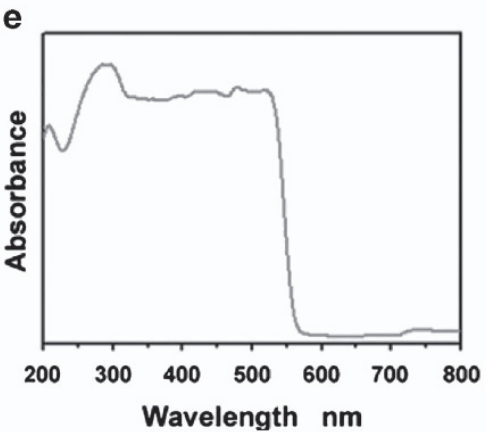

Figure 11 (a) Solar cells base on $\mathrm{CH}_{3} \mathrm{NH}_{3} \mathrm{Pbl}_{3} \mathrm{NWs}$ : SEM image, device architecture and the $\mathrm{J}-\mathrm{V}$ curve with the corresponding performance characteristics. Reproduced from Im et al. ${ }^{117}$ (b) Solar cells based on $\mathrm{CH}_{3} \mathrm{NH}_{3} \mathrm{PbBr}_{3}$ perovskite $\mathrm{NCs}$ : $\mathrm{J}-\mathrm{V}$ curve and the corresponding performance characteristics. Reproduced from Mali et al. ${ }^{33}$ (c-e) Photodetector based on $\mathrm{CH}_{3} \mathrm{NH}_{3} \mathrm{PbBr}_{3} \mathrm{NWs}$ : (c, d) SEM image of the NWs, (e) UV-visible absorption spectrum and $I-V$ curves (photoresponse) of NWs under $420 \mathrm{~nm}$ light illumination with different excitation fluences. Reproduced from Zhuo et al. ${ }^{120}$

electron transport and hole/exciton blocking layer. Integration of a bipolar host layer PVK:PBD (poly(9-vinylcarbazole):2-(4-biphenylyl)5-phenyl-1,3,4-oxadiazole) improved the film morphology, charge transport and recombination, resulting in a luminance of $10590 \mathrm{~cd} \mathrm{~m}^{-2}$ with a maximum power conversion efficiency of $1 \mathrm{~lm} \mathrm{~W}^{-1}$. The performance of LEDs depends on the radiative recombination of electrons and holes in the active layer, where the film morphology has a vital role. ${ }^{32,112}$ Incorporation of perovskite NCs into a dielectric polymer matrix may help to reduce non-radiative current losses, as demonstrated by Di et al. ${ }^{85}$ Perovskite NW arrays have also been used for the fabrication of LEDs with a device structure of glass/ITO/PEDOT:PSS/CH $\mathrm{CH}_{3} \mathrm{PbBr}_{3}-\mathrm{NWs} / \mathrm{F} 8 / \mathrm{Ca} / \mathrm{Ag}$, as demonstrated by Yang and colleagues. ${ }^{71}$

Recently, LEDs based on all-inorganic perovskite NCs have also been demonstrated. Song et al. ${ }^{35}$ reported on wavelength tunable LEDs with sharp emission spectra based on $\mathrm{CsPbX}_{3}$ NCs. For the device structure of ITO/PEDOT:PSS/PVK/QDs/TPBi/LiF/Al, the luminescence of blue, green and orange LEDs reached 742, 946 and $528 \mathrm{~cd} \mathrm{~m}^{-2}$, with external quantum efficiencies of $0.07 \%, 0.12 \%$ and $0.09 \%$, respectively. Zhang et al. ${ }^{38}$ showed how the brightness of $\mathrm{CsPbBr}_{3} \mathrm{NC}$-based green LEDs could be improved by sandwiching a thin layer of perfluorinated ionomer in between the hole-transporting and perovskite QD layers (Figures $10 \mathrm{c}$ and $\mathrm{d}$ ). The additional perfluorinated ionomer layer both increased the hole injection efficiency of the device and suppressed the charging of the emissive layer, leading to a threefold increase in the peak brightness reaching $1377 \mathrm{~cd} \mathrm{~m}^{-2}$. Li et al. ${ }^{113}$ reported on LEDs comprising large (roughly $20 \mathrm{~nm}$ ) square-shaped NCs with an electroluminescence QY of $5.7 \%$ using a device structure of glass/ITO/ZnO/CsPbX 3 QDs/ TFB polymer (poly[(9,9-dioctylfl uorenyl-2,7-diyl)-co-(4,4'-(N-(4-sec-butylphenyl) diphenylamine)] $/ \mathrm{MoO}_{3}$ (molybdenum trioxide)/Ag. Manna and colleagues $^{114}$ incorporated inorganic halide perovskite NCs of varying morphology (cubes and platelets) and halide composition (bromide and iodide) into white-light-emitting perovskite LEDs. With synthesis of perovskite NCs progressing at a torrid pace, this field will assuredly advance rapidly as well.

\section{Perovskite NCs in solar cells and photodiodes}

Perovskite-based solar cells have become one of the hottest research fields since the report published by Miyasaka and colleagues. ${ }^{6}$ Intense research efforts have led to a rapid increase in power conversion efficiencies to over $20 \%$ within a span of only 5 years, with the current certified record being listed at over $22 \%$ by Sang Il Seok's group. ${ }^{115,116}$ Although most of the reported efficient solar cell devices are based on perovskite films, there have been several recent attempts in employing perovskite NCs as active materials, too. Im et al. ${ }^{117}$ reported the fabrication of solar cells using $\mathrm{MAPbI}_{3} \mathrm{NWs}$ (Figure 11a) prepared by an aprotic solvent-assisted two-step spin coating process. The maximum power conversion efficiency of these solar cells reached $14.7 \%$ using the device architecture of $\mathrm{FTO} /$ compact $\mathrm{TiO}_{2} /$ mesoporous $\mathrm{TiO}_{2}$ $+\mathrm{MAPbI}_{3} \mathrm{NW}-\mathrm{MAPbI}_{3}+$ Spiro-MeOTAD/Au (Figure 11a). It was also found that 1D NWs exhibited faster carrier and higher lateral conductivity compared with bulk 3D perovskites. Mali et al. ${ }^{33}$ fabricated $\mathrm{MAPbBr}_{3}$ NC-based solar cells with a power conversion efficiency of $11.4 \%$ using $\mathrm{FTO} / \mathrm{Bl}-\mathrm{TiO}_{2} / \mathrm{mp}-\mathrm{TiO}_{2}+\mathrm{MAPbBr}_{3}$ $(\sim 2 \mathrm{~nm} \mathrm{NCs}) / \mathrm{PTAA} / \mathrm{Au}$ as a device configuration (Figure $11 \mathrm{~b})$. In this fabrication method, $\mathrm{MAPbBr}_{3} \mathrm{NCs}$ were prepared by spin coating a dimethyl sulfoxide solution of MA bromide and $\mathrm{PbBr}_{2}$ onto a 
mesoporous $\mathrm{TiO}_{2}$ layer followed by annealing on a hot plate. These devices were found to be stable for up to 4 months. Solar cells comprising all-inorganic perovskite $\mathrm{NCs}\left(\mathrm{CsPbI}_{3}\right)$ have reached efficiencies of $9.8 \%$, still significantly lower than solar cells made of hybrid perovskite NCs. ${ }^{118}$

Most of the semiconductor materials displaying high photoconversion efficiencies can act as efficient photodetectors. In light of this, perovskite NCs have also been employed as broadband photodetectors, even though this research field is rather new. ${ }^{119,120}$ Yang and colleagues $^{121}$ reported solution-processed photodetectors based on $\mathrm{MAPbI}_{3-x} \mathrm{Cl}_{x}$ thin films with an inverted device configuration made of glass/ITO/PEDOT:PSS/MAPbI ${ }_{3-x} \mathrm{Cl}_{x} / \mathrm{PCBM}$ ([6,6]-Phenyl-C61-butyric acid methyl ester)/PFN poly[(9,9-bis(30-( $N, N$-dimethylamino $)$ propyl)-2,7-fluorene)-alt-2,7-(9,9-dioctylfluorene)] (hole blocking layer)/Al. The photodetector operating at room temperature showed excellent detection sensitivity approaching $10^{14}$ Jones with a fast photoresponse and a linear dynamic range over $100 \mathrm{~dB}$. Perovskite NWs have also been used for the fabrication of visible-light photodetectors, as reported by Zhang and colleagues ${ }^{120}$ (Figures $11 \mathrm{c}-\mathrm{e}$ ). Their device was made by depositing perovskite NWs on a gold interdigital electrode comprising 14 pairs of fingers with adjacent intervals of $\sim 150 \mu \mathrm{m}$. $\mathrm{MAPbBr}_{3} \mathrm{NWs}$ were prepared via self-templated directed approach, in which $\mathrm{Pb}$-containing precursor NWs were first synthesized and then transformed into perovskite wires by reacting with an isopropanol solution containing $\mathrm{CH}_{3} \mathrm{NH}_{3} \mathrm{Br}$ and $\mathrm{HBr}$. Porous $\mathrm{MAPbBr}_{3}$ NWs employed in these cells exhibited superior optoelectronic activity with a fast photo-response and decay times. In spite of these early demonstrations, there is a lot of scope for improving their device performances by controlling the NC morphology and device architectures.

\section{SUMMARY AND OUTLOOK}

During the last few years, perovskite materials have received great attention; first, in the form of thin films and most recently as colloidal NCs. Our review introduces the common synthetic strategies for the fabrication and control over the size and morphology of both hybrid organic/inorganic and all-inorganic perovskite NCs. Their fascinating optical properties were investigated, both in the ensemble and on the single-particle level. These properties have inspired the use of perovskite NCs in lasers and LEDs, solar cells and photodetectors.

In spite of the impressive progress in all the areas related to perovskite NCs, there are still several challenges to be addressed. Similar to their thin film counterparts, the stability of perovskite NCs is an important issue, as they tend to degrade rapidly. Degradation can happen due to several external factors, for example, moisture, oxygen, high temperature and UV light. The related mechanisms are not yet completely understood, limiting the possibilities of preventing degradation from happening. In terms of degradation due to moisture, this is inherent to the metal halide perovskites, which are easily dissolved in polar solvents, in particularly water. UV light possibly enhances ion migration in the perovskite or leads to the formation of free radicals. In the immediate future, researchers need to focus on either encapsulating NCs to prevent degradation or changing their chemical composition to obtain an intrinsic stability, especially to high temperatures and water. In addition, the halide ion exchange in between perovskite NCs made of different halides has been detrimental to the fabrication of white LEDs. This problem requires immediate attention for advancing the field of perovskite LEDs. Very recently, we and others have demonstrated that the encapsulation of perovskite NCs in a polyhedral oligomeric silsesquioxane matrix or a mesoporous silica shell not only prevents this halide exchange, but also enhances the water resistivity of the NCs. ${ }^{122-125}$ In addition, perovskite NCs are extremely sensitive and tend to degrade or transform in to other compounds (such as metallic lead) under exposure to electron beams. ${ }^{25}$ The exact mechanisms of these transformations need to be investigated, as TEM studies are crucial for unambiguous characterization of the morphology of perovskite NCs. A recent study by Milosavljević et al. ${ }^{126}$ showed that even a low-energy electron beam can induce structural and chemical transformations in $\mathrm{MAPbI}_{3}$. The transformations were attributed to the decomposition of perovskites through the interaction of the electrons with the organic cation of perovskites, leading to the formation of $\mathrm{PbI}_{2}$ and polymer hydrocarbon residue $\left(-\mathrm{CH}_{2}-\right)$ on the surface. On the other hand, inorganic metal halide perovskites seem to be more stable under low-energy electron illumination, enabling high-resolution TEM characterization. Nevertheless, they can still degrade under a highenergy electron beam, similarly leading to the formation of small dots on the NC surface. An accurate characterization of the elemental composition after degradation of particles would provide better understanding of degradation mechanism; however, it is likely to be metallic lead or lead halide, as observed in previous studies. ${ }^{25}$

Apart from the stability issues, there are a number of other challenges related to perovskite NCs. Foremost is the desire to eliminate toxic lead from both hybrid and all-inorganic perovskites, either produced in nanoparticle form or as thin films. This is especially necessary for upscaling the perovskite fabrication for widespread photovoltaic use. There have been some attempts to use tin instead of $\mathrm{Pb}$, but this element is also not non-toxic and very unstable, as $\mathrm{Sn}$ (II) can easily be oxidized, transforming to the $\mathrm{Sn}$ (IV) state. $\mathrm{CsSnX}_{3}$ NCs have been prepared using synthesis methods developed for their lead-containing counterparts; ${ }^{67}$ however, the particles degrade within a few hours after preparation. Finding methods for enhancing the viability of lead-free perovskites deserves more attention in the future.

A better control over dimensionality and size of perovskite NCs during synthesis is one of the critical issues for understanding structure-property relationships, as well as advancing their applications. The formation of perovskites occurs extremely rapidly, making a study of the intermediate particles difficult, which could aid in understanding the growth mechanisms. Although there have been some studies showing an ability to control the shape of the perovskite particles to some degree, a full understanding of their nucleation and growth mechanisms is still lacking. Hybrid perovskite NCs seem especially difficult to control, often yielding rather polydisperse NCs, whereas inorganic NS tend to be more monodisperse with better control over size and dimensionality. Syntheses of nanoplatelets often produce mixtures of nanoplatelets with different thickness, which have proven to be difficult to separate, limiting studies aiming to understand the thickness-dependent optical properties of perovskite nanoplatelets. ${ }^{25,92}$ In spite of these difficulties, theoretical models have been developed to understand the quantum size effects of perovskite NCs and, with some improvement, experimental studies will be able to confirm or refute these results. ${ }^{25,87}$

In spite of the recent advances in synthesis, not many studies exist concerning the photophysics of perovskite NCs; this area will definitely become more active and studies exploring carrier relaxation and charge transfer processes will follow. Such studies will help us to better understand and control not only the optical properties of perovskite NCs but also their electronic character, which is necessary to maximize the efficiency in many device types. Although the recombination mechanisms of photoexcited charge carriers in perovskite bulk films are generally known, there are not many studies that have shed light on the processes occurring in perovskite NCs. 
Although bimolecular recombination is attributed to direct band-toband electron-hole recombination, mono-molecular charge recombination originates from trap states and excitonic recombination. ${ }^{127}$ With increased exciton binding energy, it is expected that excitonic recombination will dominate in NCs, whose dimensions are reduced enough to exhibit quantum confinement effect. High-quality monodisperse NCs are needed, in order to attain an unambiguous understanding of their photophysics. This will constitute an important step in advancing the utilization of perovskite NCs in modern optoelectronic devices.

An ability to perform controlled exchange of ligands to promote charge transfer in perovskite NC films is also highly desirable. Another aspect that has to be thoroughly addressed is the influence of ligands on the interfacial contacts in devices fabricated using perovskite NCs, something that is not present in the case of devices based on thin perovskite films. There have already been several studies on the development of various layers for removing or minimizing the interfacial barriers, in order to enhance device performance. ${ }^{38}$ Ligands or other specific surface coatings could potentially also help to prevent ion migration between NCs, a process limiting the use of these materials for energy transfer applications so far. Based on the optical properties and applications discussed in this review, it is obvious that metal halide perovskite NCs resemble conventional semiconductors in certain aspects, while also displaying unique properties such as ion conductivity and ease of synthesis. Therefore, much of the knowledge on conventional II-VI semiconductor NCs can be applied to perovskite analogs helping to overcome some of the challenges and advancing their device applications. For example, optimized device architectures and materials (electron and hole transport layers and electrodes) that have been widely employed for semiconductor devices can be directly tested on perovskite-based devices. ${ }^{9,117}$ Despite all of the challenges remaining, perovskites have rapidly advanced as one of the premier materials for a plethora of applications. With the vast amount of research being conducted in this field, it is to be expected that many of these challenges can be overcome rapidly, enabling consumer-friendly device applications.

\section{CONFLICT OF INTEREST}

The authors declare no conflict of interest.

\section{ACKNOWLEDGEMENTS}

This work was supported by the grant from the Research Grants Council of the Hong Kong SAR, China (project CityU 11337616), by Bavarian State Ministry of Science, Research and Arts through the grant 'Solar Technologies go Hybrid (SolTech)' and by the Alexander von Humboldt-Stiftung (LP).

1 Burschka, J., Pellet, N., Moon, S. J., Humphry-Baker, R., Gao, P., Nazeeruddin, M. K \& Gratzel, M. Sequential deposition as a route to high-performance perovskitesensitized solar cells. Nature 499, 316-319 (2013).

2 Cai, B., Xing, Y., Yang, Z., Zhang, W.-H. \& Qiu, J. High performance hybrid solar cells sensitized by organolead halide perovskites. Energy Environ. Sci. 6, 1480 (2013).

3 González-Carrero, S., Galian, R. E. \& Pérez-Prieto, J. Organometal halide perovskites: bulk low-dimension materials and nanoparticles. Part. Part. Syst. Char. 32 709-720 (2015).

4 Kim, H. S., Lee, C. R., Im, J. H., Lee, K. B., Moehl, T., Marchioro, A., Moon, S. J., Humphry-Baker, R., Yum, J. H., Moser, J. E., Gratzel, M. \& Park, N. G. Lead iodide perovskite sensitized all-solid-state submicron thin film mesoscopic solar cell with efficiency exceeding 9\%. Sci. Rep. 2, 591 (2012).

5 Deschler, F., Price, M., Pathak, S., Klintberg, L. E., Jarausch, D. D., Higler, R., Huttner, S., Leijtens, T., Stranks, S. D., Snaith, H. J., Atature, M., Phillips, R. T. \& Friend, R. H. High photoluminescence efficiency and optically pumped lasing in solution-processed mixed halide perovskite semiconductors. J. Phys. Chem. Lett. 5 , 1421-1426 (2014).
6 Kojima, A., Teshima, K., Shirai, Y. \& Miyasaka, T. Organometal halide perovskites as visible-light sensitizers for photovoltaic cells. J. Am. Chem. Soc. 131, 6050-6051 (2009).

7 Lee, M. M., Teuscher, J., Miyasaka, T., Murakami, T. N. \& Snaith, H. J. Efficient hybrid solar cells based on meso-superstructured organometal halide perovskites. Science 338, 643-647 (2012).

8 Liu, M., Johnston, M. B. \& Snaith, H. J. Efficient planar heterojunction perovskite solar cells by vapour deposition. Nature 501, 395-398 (2013).

9 Tan, Z. K., Moghaddam, R. S., Lai, M. L., Docampo, P., Higler, R., Deschler, F., Price, M., Sadhanala, A., Pazos, L. M., Credgington, D., Hanusch, F., Bein, T. Snaith, H. J. \& Friend, R. H. Bright light-emitting diodes based on organometal halide perovskite. Nat. Nanotechnol. 9, 687-692 (2014).

10 Xing, G., Mathews, N., Lim, S. S., Yantara, N., Liu, X., Sabba, D., Gratzel, M., Mhaisalkar, S. \& Sum, T. C. Low-temperature solution-processed wavelength-tunable perovskites for lasing. Nat. Mater. 13, 476-480 (2014).

11 Zhang, W. Saliba, M., Moore, D. T., Pathak, S. K., Horantner, M. T., Stergiopoulos, T., Stranks, S. D., Eperon, G. E., Alexander-Webber, J. A., Abate, A., Sadhanala, A., Yao, S., Chen, Y., Friend, R. H., Estroff, L. A., Wiesner, U. \& Snaith, H. J. Ultrasmooth organic-inorganic perovskite thin-film formation and crystallization for efficient planar heterojunction solar cells. Nat. Commun. 6, 6142 (2015).

12 Zhou, H., Chen, Q., Li, G., Luo, S., Song, T. B., Duan, H. S., Hong, Z., You, J., Liu, Y. \& Yang, Y. Photovoltaics. interface engineering of highly efficient perovskite solar cells. Science 345, 542-546 (2014).

13 Zhu, H., Fu, Y., Meng, F., Wu, X., Gong, Z., Ding, Q., Gustafsson, M. V., Trinh, M. T., Jin, S. \& Zhu, X. Y. Lead halide perovskite nanowire lasers with low lasing thresholds and high quality factors. Nat. Mater. 14, 636-642 (2015).

14 Weber, D. The Perovskite System $\mathrm{CH}_{3} \mathrm{NH}_{3}\left[\mathrm{~Pb}_{n}, \mathrm{Sn}_{1-n} \mathrm{X}_{3}\right](\mathrm{X}=\mathrm{Cl}, \mathrm{Br}, \mathrm{I})$. Z. Naturforsch. B 34, 939-941 (1979).

15 Weber, D. $\left.\mathrm{CH}_{3} \mathrm{NH}_{3} \mathrm{SnBr}_{x}\right|_{3-x}(\mathrm{X}=0-3)-\mathrm{Sn}(\mathrm{II})$-system with cubic perovskite structure. Z. Naturforsch. B 33, 862-865 (1978).

16 Weber, D. $\mathrm{CH}_{3} \mathrm{NH}_{3} \mathrm{PbX}_{3}$, a $\mathrm{Pb}(\mathrm{II})$-system with cubic perovskite structure. Z Naturforsch B 33, 1443-1445 (1978).

17 Mitzi, D. B., Feild, C. A., Harrison, W. T. A. \& Guloy, A. M. Conducting tin halides with a layered organic-based perovskite structure. Nature 369, 467-469 (1994).

18 Mitzi, D. B., Chondroudis, K. \& Kagan, C. R. Organic-inorganic electronics. IBM J. Res. Dev. 45, 29-45 (2001).

19 Mitzi, D. B., Dimitrakopoulos, C. D. \& Kosbar, L. L. Structurally tailored organicinorganic perovskites: optical properties and solution-processed channel materials for thin-film transistors. Chem. Mater. 13, 3728-3740 (2001).

20 Kojima, A., Ikegami, M., Teshima, K. \& Miyasaka, T. Highly luminescent lead bromide perovskite nanoparticles synthesized with porous alumina media. Chem. Lett. 41, 397-399 (2012).

21 Christians, J. A., Miranda Herrera, P. A. \& Kamat, P. V. Transformation of the excited state and photovoltaic efficiency of $\mathrm{CH}_{3} \mathrm{NH}_{3} \mathrm{Pbl}_{3}$ perovskite upon controlled exposure to humidified air. J. Am. Chem. Soc. 137, 1530-1538 (2015).

22 Eperon, G. E., Stranks, S. D., Menelaou, C., Johnston, M. B., Herz, L. M. \& Snaith, H. J. Formamidinium lead trihalide: a broadly tunable perovskite for efficient planar heterojunction solar cells. Energy Environ. Sci. 7, 982-988 (2014).

23 Zhang, F., Zhong, H., Chen, C., Wu, X.G., Hu, X., Huang, H., Han, J., Zou, B. \& Dong, $Y$. Brightly luminescent and color-tunable colloidal $\mathrm{CH}_{3} \mathrm{NH}_{3} \mathrm{PbX}_{3}(\mathrm{X}=\mathrm{Br}$, I, $\mathrm{CI}$ ) quantum dots: potential alternatives for display technology. ACS Nano 9, 4533-4542 (2015).

24 Protesescu, L., Yakunin, S., Bodnarchuk, M. I., Krieg, F., Caputo, R., Hendon, C. H., Yang, R. X., Walsh, A. \& Kovalenko, M. V. Nanocrystals of cesium lead halide perovskites ( $\mathrm{CsPbX}_{3}, \mathrm{X}=\mathrm{Cl}, \mathrm{Br}$, and I): novel optoelectronic materials showing bright emission with wide color gamut. Nano Lett. 15, 3692-3696 (2015).

25 Sichert, J. A., Tong, Y., Mutz, N., Vollmer, M., Fischer, S., Milowska, K. Z., García Cortadella, R., Nickel, B., Cardenas-Daw, C., Stolarczyk, J. K., Urban, A. S. \& Feldmann, J. Quantum size effect in organometal halide perovskite nanoplatelets. Nano Lett. 15, 6521-6527 (2015)

26 Sun, S., Yuan, D., Xu, Y., Wang, A. \& Deng, Z. Ligand-mediated synthesis of shape-controlled cesium lead halide perovskite nanocrystals via reprecipitation process at room temperature. ACS Nano 10, 3648-3657 (2016).

27 Wu, X., Trinh, M. T., Niesner, D., Zhu, H., Norman, Z., Owen, J. S., Yaffe, O., Kudisch, B. J. \& Zhu, X. Y. Trap States in Lead lodide Perovskites. J. Am. Chem. Soc. 137, 2089-2096 (2015).

28 Gonzalez-Carrero, S., Galian, R. E. \& Pérez-Prieto, J. Maximizing the emissive properties of $\mathrm{CH}_{3} \mathrm{NH}_{3} \mathrm{PbBr}_{3}$ perovskite nanoparticles. J. Mater. Chem. A 3, 9187-9193 (2015).

29 Huang, H., Susha, A. S., Kershaw, S. V., Hung, T. F. \& Rogach, A. L. Control of emission color of high quantum yield $\mathrm{CH}_{3} \mathrm{NH}_{3} \mathrm{PbBr}_{3}$ perovskite quantum dots by precipitation temperature. Adv. Sci. 2, 1500194 (2015).

30 Schmidt, L. C., Pertegas, A., Gonzalez-Carrero, S., Malinkiewicz, O., Agouram, S., Minguez Espallargas, G., Bolink, H. J., Galian, R. E. \& Pérez-Prieto, J. Nontemplate synthesis of $\mathrm{CH}_{3} \mathrm{NH}_{3} \mathrm{PbBr}_{3}$ perovskite nanoparticles. J. Am. Chem. Soc. 136, 850-853 (2014).

31 Eperon, G. E., Paternò, G. M., Sutton, R. J., Zampetti, A., Haghighirad, A. A., Cacialli, F. \& Snaith, H. J. Inorganic caesium lead iodide perovskite solar cells. J. Mater. Chem. A 3, 19688-19695 (2015).

32 Ling, Y., Yuan, Z., Tian, Y., Wang, X., Wang, J. C., Xin, Y., Hanson, K., Ma, B. \& Gao, H. Bright light-emitting diodes based on organometal halide perovskite nanoplatelets. Adv. Mater. 28, 305-311 (2016). 
33 Mali, S. S., Shim, C. S. \& Hong, C. K. Highly stable and efficient solid-state solar cells based on methylammonium lead bromide $\left(\mathrm{CH}_{3} \mathrm{NH}_{3} \mathrm{PbBr}_{3}\right)$ perovskite quantum dots. NPG Asia Mater. 7, e208 (2015).

34 Pan, J., Sarmah, S. P., Murali, B., Dursun, I., Peng, W., Parida, M. R., Liu, J., Sinatra, L., Alyami, N., Zhao, C., Alarousu, E., Ng, T. K., Ooi, B. S., Bakr, O. M. \& Mohammed, O. F. Air-stable surface-passivated perovskite quantum dots for ultra-robust, single- and two-photon-induced amplified spontaneous emission. J. Phys. Chem. Lett. 6, 5027-5033 (2015).

35 Song, J., Li, J., Li, X., Xu, L., Dong, Y. \& Zeng, H. Quantum dot light-emitting diodes based on inorganic perovskite cesium lead halides $\left(\mathrm{CsPbX}_{3}\right)$. Adv. Mater. 27, 7162-7167 (2015).

36 Wang, Y., Li, X., Zhao, X., Xiao, L., Zeng, H. \& Sun, H. Nonlinear absorption and low-threshold multiphoton pumped stimulated emission from all-inorganic perovskite nanocrystals. Nano Lett. 16, 448-453 (2016).

37 Yakunin, S., Protesescu, L., Krieg, F., Bodnarchuk, M. I., Nedelcu, G., Humer, M. De Luca, G., Fiebig, M., Heiss, W. \& Kovalenko, M. V. Low-threshold amplified spontaneous emission and lasing from colloidal nanocrystals of caesium lead halide perovskites. Nat. Commun. 6, 8056 (2015).

38 Zhang, X., Lin, H., Huang, H., Reckmeier, C., Zhang, Y., Choy, W. C. \& Rogach, A. L. Enhancing the brightness of cesium lead halide perovskite nanocrystal based green light-emitting devices through the interface engineering with perfluorinated ionomer. Nano Lett. 16, 1415-1420 (2016).

39 Ishihara, T., Takahashi, J. \& Goto, T. Optical properties due to electronic transitions in two-dimensional semiconductors $\left(\mathrm{C}_{n} \mathrm{H}_{2 n+1} \mathrm{NH}_{3}\right)_{2} \mathrm{Pbl}_{4}$. Phys. Rev. B 42 , 11099-11107 (1990).

40 Calabrese, J., Jones, N. L., Harlow, R. L., Herron, N., Thorn, D. L. \& Wang, Y. Preparation and characterization of layered lead halide compounds. J. Am. Chem. Soc. 113, 2328-2330 (1991).

41 Papavassiliou, G. C., Koutselas, I. B., Lagouvardos, D. J., Kapoutsis, J., Terzis, A. \& Papaioannou, G. J. Optical and related properties of some 3-dimensional and lower-dimensional semiconductor systems. Mol. Cryst. Liq. Crys. A 252, 395-404 (1994).

42 Papavassiliou, G. C. \& Koutselas, I. B. Structural, optical and related properties of some natural three- and lower-dimensional semiconductor systems. Synth. Metals 71, 1713-1714 (1995)

43 Koutselas, I. B., Ducasse, L. \& Papavassiliou, G. C. Electronic properties of three- and low-dimensional semiconducting materials with $\mathrm{Pb}$ halide and $\mathrm{Sn}$ halide units. J. Phys.Condens. Matter 8, 1217-1227 (1996).

44 Muthu, C., Nagamma, S. R. \& Nair, V. C. Luminescent hybrid perovskite nanoparticles as a new platform for selective detection of 2,4,6-trinitrophenol. RSC Adv. 4, 55908-55911 (2014).

45 Luo, B., Pu, Y.-C., Yang, Y., Lindley, S. A., Abdelmageed, G., Ashry, H., Li, Y., Li, X. \& Zhang, J. Z. Synthesis, optical properties, and exciton dynamics of organolead bromide perovskite nanocrystals. J. Phys. Chem. C 119, 26672-26682 (2015).

46 Tyagi, P., Arveson, S. M. \& Tisdale, W. A. Colloidal organohalide perovskite nanoplatelets exhibiting quantum confinement. J. Phys. Chem. Lett. 6, 1911-1916 (2015).

47 Tanaka, K., Takahashi, T., Ban, T., Kondo, T., Uchida, K. \& Miura, N. Comparative study on the excitons in lead-halide-based perovskite-type crystals $\mathrm{CH}_{3} \mathrm{NH}_{3} \mathrm{PbBr}_{3}$ $\mathrm{CH}_{3} \mathrm{NH}_{3} \mathrm{Pbl}_{3}$. Solid State Commun. 127, 619-623 (2003).

48 Buin, A., Comin, R., Ip, A. H. \& Sargent, E. H. Perovskite quantum dots modeled using ab initio and replica exchange molecular dynamics. J. Phys. Chem. C 119, 13965-13971 (2015).

49 Huang, H., Zhao, F., Liu, L., Zhang, F., Wu, X. G., Shi, L., Zou, B., Pei, Q. \& Zhong, H. Emulsion synthesis of size-tunable $\mathrm{CH}_{3} \mathrm{NH}_{3} \mathrm{PbBr}_{3}$ quantum dots: an alternative route toward efficient light-emitting diodes. ACS Appl. Mater. Interfaces 7, 28128-28133 (2015).

50 Naphade, R., Nagane, S., Shanker, G. S., Fernandes, R., Kothari, D., Zhou, Y., Padture, N. P. \& Ogale, S. Hybrid perovskite quantum nanostructures synthesized by electrospray antisolvent-solvent extraction and intercalation. ACS Appl. Mater. Interfaces 8, 854-861 (2016).

51 Vybornyi, O., Yakunin, S. \& Kovalenko, M. V. Polar-solvent-free colloidal synthesis of highly luminescent alkylammonium lead halide perovskite nanocrystals. Nanoscale $\mathbf{8}$, 6278-6283 (2016).

52 Audebert, P., Clavier, G., Alain-Rizzo, V. R., Deleporte, E., Zhang, S., Lauret, J.-S. B., Lanty, G. T. \& Boissière, C. D. Synthesis of new perovskite luminescent nanoparticles in the visible range. Chem. Mater. 21, 210-214 (2009).

53 Papavassiliou, G. C., Pagona, G., Karousis, N., Mousdis, G. A., Koutselas, I. \& Vassilakopoulou, A. Nanocrystalline/microcrystalline materials based on leadhalide units. J. Mater. Chem. 22, 8271 (2012).

54 Saikumar, I., Ahmad, S., Baumberg, J. J. \& Vijaya Prakash, G. Fabrication of excitonic luminescent inorganic-organic hybrid nano- and microcrystals. Script. Mater. 67, 834-837 (2012).

55 Chen, Z., Li, H., Tang, Y., Huang, X., Ho, D. \& Lee, C.-S. Shape-controlled synthesis of organolead halide perovskite nanocrystals and their tunable optical absorption. Mater. Res. Express 1, 015034 (2014)

56 Zhu, F., Men, L., Guo, Y., Zhu, Q., Bhattacharjee, U., Goodwin, P. M., Petrich, J. W., Smith, E. A. \& Vela, J. Shape evolution and single particle luminescence of organometal halide perovskite nanocrystals. ACS Nano 9, 2948-2959 (2015).

57 Spina, M., Bonvin, E., Sienkiewicz, A., Forro, L. \& Horvath, E. Controlled growth of $\mathrm{CH}_{3} \mathrm{NH}_{3} \mathrm{Pbl}_{3}$ nanowires in arrays of open nanofluidic channels. Sci. Rep. 6, 19834 (2016).
58 Zhu, P., Gu, S., Shen, X., Xu, N., Tan, Y., Zhuang, S., Deng, Y., Lu, Z., Wang, Z. \& Zhu, J. Direct conversion of perovskite thin films into nanowires with kinetic control for flexible optoelectronic devices. Nano Lett. 16, 871-876 (2016).

59 Yuan, Z., Shu, Y., Tian, Y., Xin, Y. \& Ma, B. A facile one-pot synthesis of deep blue luminescent lead bromide perovskite microdisks. Chem. Commun. 51, 16385-16388 (2015).

60 Yuan, Z., Shu, Y., Xin, Y. \& Ma, B. Highly luminescent nanoscale quasi-2D layered lead bromide perovskites with tunable emissions. Chem. Commun. 52, 3887-3890 (2016).

61 Lignos, I., Stavrakis, S., Nedelcu, G., Protesescu, L., deMello, A. J. \& Kovalenko, M. V. Synthesis of cesium lead halide perovskite nanocrystals in a droplet-based microfluidic platform: fast parametric space mapping. Nano Lett. 16, 1869-1877 (2016).

62 Koolyk, M., Amgar, D., Aharon, S. \& Etgar, L. Kinetics of cesium lead halide perovskite nanoparticle growth; focusing and de-focusing of size distribution. Nanoscale 8, 6403-6409 (2016).

63 Zhang, D., Eaton, S. W., Yu, Y., Dou, L. \& Yang, P. Solution-phase synthesis of cesium lead halide perovskite nanowires. J. Am. Chem. Soc. 137, 9230-9233 (2015).

$64 \mathrm{Li}, \mathrm{X}$., Wu, Y., Zhang, S., Cai, B., Gu, Y., Song, J. \& Zeng, H. CsPbX 3 quantum dots for lighting and displays: room-temperature synthesis, photoluminescence superiorities, underlying origins and white light-emitting diodes. Adv. Funct. Mater. 26, 2435-244510 (2016).

65 Akkerman, Q. A., Motti, S. G., Srimath Kandada, A. R., Mosconi, E., D'Innocenzo, V., Bertoni, G., Marras, S., Kamino, B. A., Miranda, L., De Angelis, F., Petrozza, A., Prato, M. \& Manna, L. Solution synthesis approach to colloidal cesium lead halide perovskite nanoplatelets with monolayer-level thickness control. J. Am. Chem. Soc. 138, 1010-1016 (2016).

66 Wang, K.-H., Wu, L., Li, L., Yao, H.-B., Qian, H.-S. \& Yu, S.-H. Large-scale synthesis of highly luminescent perovskite-related $\mathrm{cspb}_{2} \mathrm{br}_{5}$ nanoplatelets and their fast anion exchange. Angew. Chem. Int. Ed. 55, 8328-8332 (2016).

67 Jellicoe, T. C., Richter, J. M., Glass, H. F. J., Tabachnyk, M., Brady, R., Dutton, S. E., Rao, A., Friend, R. H., Credgington, D., Greenham, N. C. \& Böhm, M. L. Synthesis and optical properties of lead-free cesium tin halide perovskite nanocrystals. J. Am. Chem. Soc. 138, 2941-2944 (2016).

68 Nedelcu, G., Protesescu, L., Yakunin, S., Bodnarchuk, M. I., Grotevent, M. J. \& Kovalenko, M. V. Fast anion-exchange in highly luminescent nanocrystals of cesium lead halide perovskites $\left(\mathrm{CsPbX}_{3}, \mathrm{X}=\mathrm{Cl}, \mathrm{Br}, \mathrm{I}\right)$. Nano Lett. 15, 5635-5640 (2015).

69 Akkerman, Q. A., D'Innocenzo, V., Accornero, S., Scarpellini, A., Petrozza, A., Prato, M. \& Manna, L. Tuning the optical properties of cesium lead halide perovskite nanocrystals by anion exchange reactions. J. Am. Chem. Soc. 137, 10276-10281 (2015).

70 Jang, D. M., Park, K., Kim, D. H., Park, J., Shojaei, F., Kang, H. S., Ahn, J. P., Lee, J. W. \& Song, J. K. Reversible halide exchange reaction of organometal trihalide perovskite colloidal nanocrystals for full-range band gap tuning. Nano Lett. 15, 5191-5199 (2015).

71 Wong, A. B., Lai, M., Eaton, S. W., Yu, Y., Lin, E., Dou, L., Fu, A. \& Yang, P. Growth and anion exchange conversion of $\mathrm{CH}_{3} \mathrm{NH}_{3} \mathrm{PbX}_{3}$ nanorod arrays for lightemitting diodes. Nano Lett. 15, 5519-5524 (2015).

72 Wu, K., Bera, A., Ma, C., Du, Y., Yang, Y., Li, L. \& Wu, T. Temperature-dependent excitonic photoluminescence of hybrid organometal halide perovskite films. Phys. Chem. Chem. Phys. 16, 22476-22481 (2014).

73 Fang, H.-H., Raissa, R., Abdu-Aguye, M., Adjokatse, S., Blake, G. R., Even, J. \& Loi, M. A. Photophysics of organic-inorganic hybrid lead iodide perovskite single crystals. Adv. Funct. Mater. 25, 2378-2385 (2015).

74 Herz, L. M. Charge-carrier dynamics in organic-inorganic metal halide perovskites. Annu. Rev. Phys. Chem. 67, 65-89 (2016).

75 Manser, J. S., Christians, J. A. \& Kamat, P. V. Intriguing optoelectronic properties of metal halide perovskites. Chem. Rev. (e-pub ahead of print 21 June 2016; doi:10.1021/acs.chemrev.6b00136).

76 Sum, T. C., Mathews, N., Xing, G., Lim, S. S., Chong, W. K., Giovanni, D. \& Dewi, H. A. Spectral features and charge dynamics of lead halide perovskites: origins and interpretations. Acc. Chem. Res. 49, 294-302 (2016).

77 Even, J., Pedesseau, L. \& Katan, C. Analysis of multivalley and multibandgap absorption and enhancement of free carriers related to exciton screening in hybrid perovskites. J. Phys. Chem. C 118, 11566-11572 (2014).

78 Milot, R. L., Eperon, G. E., Snaith, H. J., Johnston, M. B. \& Herz, L. M. Temperaturedependent charge-carrier dynamics in $\mathrm{CH}_{3} \mathrm{NH}_{3} \mathrm{Pbl}_{3}$ perovskite thin films. Adv. Funct. Mater. 25, 6218-6227 (2015).

79 Feldmann, J., Peter, G., Göbel, E. O., Dawson, P., Moore, K., Foxon, C. \& Elliott, R. J. Linewidth dependence of radiative exciton lifetimes in quantum wells. Phys. Rev. Lett. 59, 2337-2340 (1987).

80 Bawendi, M. G., Steigerwald, M. L. \& Brus, L. E. The quantum mechanics of larger semiconductor clusters ('quantum dots'). Annu. Rev. Phys. Chem. 41, 477-496 (1990).

81 Talapin, D. V., Lee, J. S., Kovalenko, M. V. \& Shevchenko, E. V. Prospects of colloidal nanocrystals for electronic and optoelectronic applications. Chem. Rev. 110, 389-458 (2010).

82 Alivisatos, A. P. Semiconductor clusters, nanocrystals, and quantum dots. Science 271, 933-937 (1996).

83 Ishihara, T. Optical properties of Pbl-based perovskite structures. J. Lumin. 60-61, 269-274 (1994).

84 Ishihara, T., Takahashi, J. \& Goto, T. Exciton state in two-dimensional perovskite semiconductor $\left(\mathrm{C}_{10} \mathrm{H}_{21} \mathrm{NH}_{3}\right)_{2} \mathrm{Pbl}_{4}$. Solid State Commun. 69, 933-936 (1989). 
85 Di, D., Musselman, K. P., Li, G., Sadhanala, A., levskaya, Y., Song, Q., Tan, Z. K., Lai, M. L., MacManus-Driscoll, J. L., Greenham, N. C. \& Friend, R. H. Size-dependent photon emission from organometal halide perovskite nanocrystals embedded in an organic matrix. J. Phys. Chem. Lett. 6, 446-450 (2015).

86 Hassan, Y., Song, Y., Pensack, R. D., Abdelrahman, A. I., Kobayashi, Y., Winnik, M. A. \& Scholes, G. D. Structure-tuned lead halide perovskite nanocrystals. Adv. Mater. 28 566-573 (2016)

87 Sapori, D., Kepenekian, M., Pedesseau, L., Katan, C. \& Even, J. Quantum confinement and dielectric profiles of colloidal nanoplatelets of halide inorganic and hybrid organic-inorganic perovskites. Nanoscale 8, 6369-6378 (2016).

88 Hong, X., Ishihara, T. \& Nurmikko, A. V. Dielectric confinement effect on excitons in $\mathrm{Pbl}_{4}$-based layered semiconductors. Phys. Rev. B 45, 6961-6964 (1992).

89 Kitazawa, N. Excitons in two-dimensional layered perovskite compounds: $\left(\mathrm{C}_{6} \mathrm{H}_{5} \mathrm{C}_{2} \mathrm{H}_{4} \mathrm{NH}_{3}\right)_{2} \mathrm{~Pb}(\mathrm{Br}, \mathrm{I})_{4}$ and $\left(\mathrm{C}_{6} \mathrm{H}_{5} \mathrm{C}_{2} \mathrm{H}_{4} \mathrm{NH}_{3}\right)_{2} \mathrm{~Pb}(\mathrm{Cl}, \mathrm{Br})_{4}$. Mat. Sci. Eng. B Solid 49, 233-238 (1997)

90 Pathak, S., Sakai, N., Wisnivesky Rocca Rivarola, F., Stranks, S. D., Liu, J., Eperon, G. E., Ducati, C., Wojciechowski, K., Griffiths, J. T., Haghighirad, A. A., Pellaroque, A., Friend, R. H. \& Snaith, H. J. Perovskite crystals for tunable white light emission. Chem. Mater. 27, 8066-8075 (2015).

91 Dou, L., Wong, A. B., Yu, Y., Lai, M., Kornienko, N., Eaton, S. W., Fu, A., Bischak, C. G., Ma, J., Ding, T., Ginsberg, N. S., Wang, L. W., Alivisatos, A. P. \& Yang, P. Atomically thin two-dimensional organic-inorganic hybrid perovskites. Science 349, 1518-1521 (2015).

92 Bekenstein, Y., Koscher, B. A., Eaton, S. W., Yang, P. \& Alivisatos, A. P. Highly luminescent colloidal nanoplates of perovskite cesium lead halide and their oriented assemblies. J. Am. Chem. Soc. 137, 16008-16011 (2015).

93 Shamsi, J., Dang, Z., Bianchini, P., Canale, C., Stasio, F. D., Brescia, R., Prato, M. \& Manna, L. Colloidal synthesis of quantum confined single crystal CsPbBr3 nanosheets with lateral size control up to the micrometer range. J. Am. Chem. Soc. 138, 7240-7243 (2016)

94 Hu, F., Zhang, H., Sun, C., Yin, C., Lv, B., Zhang, C., Yu, W. W., Wang, X., Zhang, Y. \& Xiao, M. Superior optical properties of perovskite nanocrystals as single photon emitters. ACS Nano 9, 12410-12416 (2015).

95 Park, Y. S., Guo, S., Makarov, N. S. \& Klimov, V. I. Room temperature single-photon emission from individual perovskite quantum dots. ACS Nano 9, 10386-10393 (2015).

96 Swarnkar, A., Chulliyil, R., Ravi, V. K., Irfanullah, M., Chowdhury, A. \& Nag, A. Colloidal $\mathrm{CsPbBr}_{3}$ perovskite nanocrystals: luminescence beyond traditional quantum dots. Angew. Chem. Int. Ed. 54, 15424-15428 (2015).

97 Tachikawa, T., Karimata, I. \& Kobori, Y. Surface charge trapping in organolead halide perovskites explored by single-particle photoluminescence imaging. J. Phys. Chem. Lett. 6, 3195-3201 (2015).

98 Tian, Y., Merdasa, A., Peter, M., Abdellah, M., Zheng, K., Ponseca, C. S. Jr, Pullerits, T., Yartsev, A., Sundstrom, V. \& Scheblykin, I. G. Giant photoluminescence blinking of perovskite nanocrystals reveals single-trap control of luminescence. Nano Lett. 15, 1603-1608 (2015).

99 Zheng, K., Zhu, Q., Abdellah, M., Messing, M. E., Zhang, W., Generalov, A., Niu, Y., Ribaud, L., Canton, S. E. \& Pullerits, T. Exciton binding energy and the nature of emissive states in organometal halide perovskites. J. Phys. Chem. Lett. 6, 2969-2975 (2015).

100 Tian, W. M., Zhao, C. Y., Leng, J., Gui, R. R. \& Jin, S. G. Visualizing carrier diffusion in individual single-crystal organolead halide perovskite nanowires and nanoplates. J. Am. Chem. Soc. 137, 12458-12461 (2015).

101 Tang, J. \& Marcus, R. A. Mechanisms of fluorescence blinking in semiconductor nanocrystal quantum dots. J. Chem. Phys. 123, 054704 (2005).

102 Galland, C., Ghosh, Y., Steinbruck, A., Sykora, M., Hollingsworth, J. A., Klimov, V. I. \& Htoon, $\mathrm{H}$. Two types of luminescence blinking revealed by spectroelectrochemistry of single quantum dots. Nature 479, 203-207 (2011).

103 Zhao, J., Nair, G., Fisher, B. R. \& Bawendi, M. G. Challenge to the charging model of semiconductor-nanocrystal fluorescence intermittency from off-state quantum yields and multiexciton blinking. Phys. Rev. Lett. 104, 157403 (2010).

104 Rosen, S., Schwartz, O. \& Oron, D. Transient fluorescence of the off state in blinking $\mathrm{CdSe} / \mathrm{CdS} / \mathrm{ZnS}$ semiconductor nanocrystals is not governed by Auger recombination. Phys. Rev. Lett. 104, 157404 (2010).

105 Rainò, G., Nedelcu, G., Protesescu, L., Bodnarchuk, M. I., Kovalenko, M. V., Mahrt, R. F. \& Stöferle, T. Single cesium lead halide perovskite nanocrystals at low temperature: fast single-photon emission, reduced blinking, and exciton fine structure. ACS Nano 10, 2485-2490 (2016).

106 Fu, Y., Zhu, H., Schrader, A. W., Liang, D., Ding, Q., Joshi, P., Hwang, L., Zhu, X. Y. \& Jin, S. Nanowire lasers of formamidinium lead halide perovskites and their stabilized alloys with improved stability. Nano Lett. 16, 1000-1008 (2016).

107 Gu, Z., Wang, K., Sun, W., Li, J., Liu, S., Song, Q. \& Xiao, S. Two-photon pumped $\mathrm{CH}_{3} \mathrm{NH}_{3} \mathrm{PbBr}_{3}$ perovskite microwire lasers. Adv. Opt. Mater. 4, 472-479 (2016).

108 Xing, J., Liu, X. F., Zhang, Q., Ha, S. T., Yuan, Y. W., Shen, C., Sum, T. C. \& Xiong, Q. Vapor phase synthesis of organometal halide perovskite nanowires for tunable room-temperature nanolasers. Nano Lett. 15, 4571-4577 (2015).
109 Liao, Q., Hu, K., Zhang, H., Wang, X., Yao, J. \& Fu, H. Perovskite microdisk microlasers self-assembled from solution. Adv. Mater. 27, 3405-3410 (2015).

110 Xu, Y., Chen, Q., Zhang, C., Wang, R., Wu, H., Zhang, X., Xing, G., Yu, W. W., Wang, X., Zhang, Y. \& Xiao, M. Two-photon-pumped perovskite semiconductor nanocrystal lasers. J. Am. Chem. Soc. 138, 3761-3768 (2016).

111 Era, M., Morimoto, S., Tsutsui, T. \& Saito, S. Organic-inorganic heterostructure electroluminescent device using a layered perovskite semiconductor (C6H5C2H4NH3)2Pbl4. Appl. Phys. Lett. 65, 676 (1994).

$112 \mathrm{Hu}, \mathrm{M} ., \mathrm{Bi}, \mathrm{C}$. , Yuan, Y., Bai, Y. \& Huang, J. Stabilized wide bandgap MAPbBr $\mathrm{I}_{3-x}$ perovskite by enhanced grain size and improved crystallinity. Adv. Sci. 3, 1500301 (2015)

113 Li, G., Rivarola, F. W., Davis, N. J., Bai, S., Jellicoe, T. C., de la Pena, F., Hou, S. Ducati, C., Gao, F., Friend, R. H., Greenham, N. C. \& Tan, Z. K. Highly efficient perovskite nanocrystal light-emitting diodes enabled by a universal crosslinking method. Adv. Mater. 28, 3528-3534 (2016).

114 Palazon, F., Di Stasio, F., Akkerman, Q. A., Krahne, R., Prato, M. \& Manna, L. Polymer-free films of inorganic halide perovskite nanocrystals as UV-to-white colorconversion layers in LEDs. Chem. Mater. 28, 2902-2906 (2016).

115 National Renewable Energy Laboratory Best Research-Cell Efficiencies. http://www. nrel.gov/ncpv/images/efficiency_chart.jpg Accessed: 11 March (2016).

116 Zhou, Y. \& Zhu, K. Perovskite solar cells shine in the 'valley of the sun'. ACS Energy Lett. 1, 64-67 (2016).

117 Im, J. H., Luo, J., Franckevicius, M., Pellet, N., Gao, P., Moehl, T., Zakeeruddin, S. M., Nazeeruddin, M. K., Gratzel, M. \& Park, N. G. Nanowire perovskite solar cell. Nano Lett. 15, 2120-2126 (2015).

118 Sutton, R. J., Eperon, G. E., Miranda, L., Parrott, E. S., Kamino, B. A., Patel, J. B. Hörantner, M. T., Johnston, M. B., Haghighirad, A. A., Moore, D. T. \& Snaith, H. J. Bandgap-tunable cesium lead halide perovskites with high thermal stability for efficient solar cells. Adv. Energy Mater. 6, 1502458 (2016).

119 Ha, S. T., Liu, X. F., Zhang, Q., Giovanni, D., Sum, T. C. \& Xiong, Q. H. Synthesis of organic-inorganic lead halide perovskite nanoplatelets: towards high-performance perovskite solar cells and optoelectronic devices. Adv. Opt. Mater. 2, 838-844 (2014).

120 Zhuo, S., Zhang, J., Shi, Y., Huang, Y. \& Zhang, B. Self-template-directed synthesis of porous perovskite nanowires at room temperature for high-performance visible-light photodetectors. Angew. Chem. Int. Ed. 54, 5693-5696 (2015).

121 Dou, L., Yang, Y. M., You, J., Hong, Z., Chang, W. H., Li, G. \& Yang, Y. Solution-processed hybrid perovskite photodetectors with high detectivity. Nat. Commun. 5, 5404 (2014).

122 Huang, H., Chen, B., Wang, Z., Hung, T. F., Susha, A. S., Zhong, H. \& Rogach, A. L. Water resistant $\mathrm{CsPbX}_{3}$ nanocrystals coated with polyhedral oligomeric silsesquioxane and their use as solid state luminophores in all-perovskite white light-emitting devices. Chem. Sci. 7, 5699-5703 (2016).

123 Wang, H.-C., Lin, S.-Y., Tang, A.-C., Singh, B. P., Tong, H.-C., Chen, C.-Y., Lee, Y.-C. Tsai, T.-L. \& Liu, R.-S. Mesoporous silica particles integrated with all-inorganic $\mathrm{CsPbBr} 3$ perovskite quantum-dot nanocomposites (MP-PQDs) with high stability and wide color gamut used for backlight display. Angew. Chem. Int. Ed. 55, 7924-7929 (2016)

124 Luo, B., Pu, Y.-C., Lindley, S. A., Yang, Y., Lu, L., Li, Y., Li, X. \& Zhang, J.Z. Organolead halide perovskite nanocrystals: branched capping ligands control crystal size and stability. Angew. Chem. Int. Ed. 55, 8864-8868 (2016).

125 Huang, S., Li, Z., Kong, L., Zhu, N., Shan, A. \& Li, L. Enhancing the stability of $\mathrm{CH}_{3} \mathrm{NH}_{3} \mathrm{PbBr}_{3}$ quantum dots by embedding in silica spheres derived from tetramethyl orthosilicate in 'waterless' toluene. J. Am. Chem. Soc. 138, 5749-5752 (2016).

126 Milosavljević, A. R., Huang, W., Sadhu, S. \& Ptasinska, S. Low-energy electron-induced transformations in organolead halide perovskite. Angew. Chem. Int. Ed. 55, 10083-10087 (2016).

127 Johnston, M. B. \& Herz, L. M. Hybrid perovskites for photovoltaics: charge-carrier recombination, diffusion, and radiative efficiencies. Acc. Chem. Res. 49, 146-154 (2016).

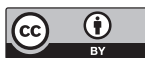

This work is licensed under a Creative Commons Attribution 4.0 International License. The images or other third party material in this article are included in the article's Creative Commons license, unless indicated otherwise in the credit line; if the material is not included under the Creative Commons license, users will need to obtain permission from the license holder to reproduce the material. To view a copy of this license, visit http:// creativecommons.org/licenses/by/4.0/

(C) The Author(s) 2016 